\title{
Essential oils in food preservation: mode of action, synergies, and interactions with food matrix components
}

\author{
Morten Hyldgaard ${ }^{1,2,3}$,Tina Mygind ${ }^{3}$ and Rikke Louise Meyer ${ }^{1,2 *}$ \\ 1 Interdisciplinary Nanoscience Center, Aarhus University, Aarhus C, Denmark \\ ${ }^{2}$ Department of Bioscience, Aarhus University, Aarhus C, Denmark \\ ${ }^{3}$ Danisco A/S, Brabrand, Denmark
}

Edited by:

Mirian A. F. Hayashi, Universidade

Federal de São Paulo, Brazil

\section{Reviewed by:}

Charles Knapp, University of

Strathclyde, UK

Dmitri Debabov, NovaBay

Pharmaceuticals, USA

*Correspondence:

Rikke Louise Meyer, Department of Bioscience, Aarhus University, Ny Munkegade, Building 540, DK-8000 Aarhus $C$, Denmark.

e-mail: rikke.meyer@inano.au.dk
Essential oils are aromatic and volatile liquids extracted from plants. The chemicals in essential oils are secondary metabolites, which play an important role in plant defense as they often possess antimicrobial properties. The interest in essential oils and their application in food preservation has been amplified in recent years by an increasingly negative consumer perception of synthetic preservatives. Furthermore, food-borne diseases are a growing public health problem worldwide, calling for more effective preservation strategies. The antibacterial properties of essential oils and their constituents have been documented extensively. Pioneering work has also elucidated the mode of action of a few essential oil constituents, but detailed knowledge about most of the compounds' mode of action is still lacking. This knowledge is particularly important to predict their effect on different microorganisms, how they interact with food matrix components, and how they work in combination with other antimicrobial compounds. The main obstacle for using essential oil constituents as food preservatives is that they are most often not potent enough as single components, and they cause negative organoleptic effects when added in sufficient amounts to provide an antimicrobial effect. Exploiting synergies between several compounds has been suggested as a solution to this problem. However, little is known about which interactions lead to synergistic, additive, or antagonistic effects. Such knowledge could contribute to design of new and more potent antimicrobial blends, and to understand the interplay between the constituents of crude essential oils. The purpose of this review is to provide an overview of current knowledge about the antibacterial properties and antibacterial mode of action of essential oils and their constituents, and to identify research avenues that can facilitate implementation of essential oils as natural preservatives in foods.

Keywords: antimicrobial, mode of action, synergy, terpenes, terpenoids, phenylpropenes, carvacrol, thymol

\section{INTRODUCTION}

Essential oils are aromatic and volatile liquids extracted from plant material, such as flowers, roots, bark, leaves, seeds, peel, fruits, wood, and whole plant (Deans and Ritchie, 1987; Hammer et al., 1999; Sánchez et al., 2010). Essential oils have been used for centuries in medicine, perfumery, cosmetic, and have been added to foods as part of spices or herbs. Their initial application was in medicine, but in the nineteenth century their use as aroma and flavor ingredients increased and became their major employment. Almost 3000 different essential oils are known, and 300 are used commercially in the flavor and fragrances market (Burt, 2004).

Essential oils are considered to be secondary metabolites and important for plant defense as they often possess antimicrobial properties (Fraenkel, 1959; Tajkarimi et al., 2010). The antibacterial properties of secondary metabolites were first evaluated using essential oil vapors by De la Croix in 1881 (Burt, 2004). Since then, essential oils or their components have been shown to not only possess broad-range antibacterial properties (Deans and Ritchie, 1987; Oussalah et al., 2007), but also antiparasitic (George et al., 2009), insecticidal (Essam, 2001; Kim et al., 2003), antiviral (Schnitzler et al., 2011), antifungal (Fitzgerald et al., 2003; Kalemba and Kunicka, 2003; Silva et al., 2011; Tserennadmid et al., 2011), and antioxidant (Brenes and Roura, 2010) properties. Furthermore, they also function as growth enhancers for animals (Brenes and Roura, 2010; Ahmadifar et al., 2011).

Although the food industry primarily uses essential oils as flavorings, they represent an interesting source of natural antimicrobials for food preservation. However, application of essential oils as food preservatives requires detailed knowledge about their properties, i.e., the minimum inhibitory concentration (MIC), the range of target organisms, the mode of action, and the effect of food matrix components on their antimicrobial properties. The purpose of this review is to provide an overview of current knowledge about the antimicrobial mode of action of essential oil constituents, and to identify research avenues that can facilitate implementation of essential oil constituents as natural food preservatives in foods.

\section{ESSENTIAL OIL CONSTITUENT CLASSES: THEIR ANTIMICROBIAL ACTIVITY AND MODE OF ACTION}

Plants produce a variety of compounds with antimicrobial activity. Some are always present while others are produced in response 
to microbial invasion or physical injury (Roller, 2003). Identifying the most active antimicrobial compounds of essential oils is cumbersome because essential oils are complex mixtures of up to 45 different constituents (Delaquis et al., 2002; Djenane et al., 2011; Espina et al., 2011), and the composition of a particular essential oil may vary depending on the season of harvest, and the methods used to extract the oil (Nannapaneni et al., 2009; Pereira and Meireles, 2010; Sánchez et al., 2010; Demuner et al., 2011; Djenane et al., 2011; Paibon et al., 2011). Essential oil constituents are a diverse family of low molecular weight organic compounds with large differences in antimicrobial activity. The active compounds can be divided into four groups according to their chemical structure: terpenes, terpenoids, phenylpropenes, and "others." This section will provide an overview of what is currently known about the antimicrobial properties and the mode of action of selected essential oil constituents. Although studies have been performed on the mode of action of some essential oils (Table 1), analyzing the mode of action behind each constituent in the oils can reveal details of its antimicrobial properties that might be concealed when studied in a mixture with many other compounds. We will thus focus this review on the individual constituents of essential oils.

Most studies concerning the antimicrobial mode of action of essential oil constituents have been performed on bacteria, while less is known about their action on yeast and molds. Gramnegative bacteria are generally less susceptible than Gram-positive bacteria (Trombetta et al., 2005). The outer membrane of Gramnegative bacteria contain hydrophilic lipopolysaccharides (LPS), which create a barrier toward macromolecules and hydrophobic compounds, providing Gram-negative bacteria with higher tolerance toward hydrophobic antimicrobial compounds like those found in essential oils (Nikaido, 1994, 2003). Most essential oil constituents have several targets (Table 2). It is therefore difficult to predict how susceptible a microorganism is and why the susceptibility varies from strain to strain. Predictions about the mode of action of crude essential oils require thorough investigations of their constituents' target site, their mode of action, and their interactions with the surrounding environment. In this context, the following is known about the mode of action of some selected essential oil constituents.

\section{TERPENES}

Terpenes are hydrocarbons produced from combination of several isoprene units $\left(\mathrm{C}_{5} \mathrm{H}_{8}\right)$. Terpenes are synthesized in the cytoplasm of plant cells, and the synthesis proceeds via the mevalonic acid pathway starting from acetyl-CoA. Terpenes have a hydrocarbon backbone which can be rearranged into cyclic structures by cyclases, thus forming monocyclic or bicyclic structures (Caballero et al., 2003). The main terpenes are monoterpenes $\left(\mathrm{C}_{10} \mathrm{H}_{16}\right)$ and sesquiterpene $\left(\mathrm{C}_{15} \mathrm{H}_{24}\right)$, but longer chains such as diterpenes $\left(\mathrm{C}_{20} \mathrm{H}_{32}\right)$, triterpenes $\left(\mathrm{C}_{30} \mathrm{H}_{40}\right)$, etc., also exist. Examples of terpenes include $p$-cymene, limonene, terpinene, sabinene, and pinene (Figure 1).

Terpenes do not represent a group of constituents with high inherent antimicrobial activity. For example, $p$-cymene, one of the major constituents in thyme, had no antimicrobial activity against several Gram-negative pathogens even at $85700 \mu \mathrm{g} / \mathrm{mL}$ concentration (Bagamboula et al., 2004). In a large scale experiment, limonene, $\alpha$-pinene, $\beta$-pinene, $\delta$-3-carene, $(+)$-sabinene, and $\alpha$ terpinene showed no or low antimicrobial activity against 25 different genera of bacteria that pose problems in animals, plants, and food products (Dorman and Deans, 2000). Koutsoudaki et al. (2005) compared the effect of $\alpha$-pinene, $\beta$-pinene, $p$-cymene, $\beta$-myrcene, $\beta$-caryophyllene, limonene, and $\gamma$-terpinene against Escherichia coli, Staphylococcus aureus, and Bacillus cereus, and their antimicrobial activity were low or absent. $p$-Cymene and $\gamma$-terpinene were ineffective as fungicides against Saccharomyces cerevisiae (Rao et al., 2010). These in vitro tests indicate that terpenes are inefficient as antimicrobials when applied as single compounds.

\section{p-Cymene}

The carvacrol precursor $p$-cymene is a monoterpene that has a benzene ring without any functional groups on its side chains. $p$-Cymene is not an efficient antimicrobial compound when used alone (Juven et al., 1994; Mann et al., 2000; Aligiannis et al., 2001; Bagamboula et al., 2004), but it potentiate the activity of compounds like carvacrol (Ultee et al., 2002; Rattanachaikunsopon and Phumkhachorn, 2010) and polymyxin B nonapeptide (Mann et al., 2000).

Several studies indicate that $p$-cymene is likely to act as a substitutional impurity in the membrane, which partly perturbs the membrane of microorganisms. $p$-Cymene has a high affinity for membranes and causes membrane expansion and affect the membrane potential of intact cells (Ultee et al., 2002). Investigations on cell and vesicle systems confirm that $p$-cymene has no effect on the membrane permeability, but cause a decrease in the enthalpy and melting temperature of membranes (Cristani et al., 2007), supporting the hypothesis that $p$-cymene acts as a substitutional impurity in the membrane.

Even though the action of $p$-cymene on the cell membrane is well established, its effect on protein synthesis and cell motility has also been investigated. $p$-Cymene had a negligible effect on the protein synthesis of E. coli cells (Burt et al., 2007), while its effect on the membrane potential resulted in decreased cell motility, as a proton motive force is needed for flagellar movement (Gabel and Berg, 2003; Burt et al., 2007).

\section{TERPENOIDS}

Terpenoids are terpenes that undergo biochemical modifications via enzymes that add oxygen molecules and move or remove methyl groups (Caballero et al., 2003). Terpenoids can be subdivided into alcohols, esters, aldehydes, ketones, ethers, phenols, and epoxides. Examples of terpenoids are: thymol, carvacrol, linalool, linalyl acetate, citronellal, piperitone, menthol, and geraniol (Figure 1).

The antimicrobial activity of most terpenoids is linked to their functional groups, and it has been shown that the hydroxyl group of phenolic terpenoids and the presence of delocalized electrons are important for antimicrobial activity. For example, the antimicrobial activity of the carvacrol derivatives carvacrol methyl ether and $p$-cymene were much lower than carvacrol (Dorman and Deans, 2000; Ultee et al., 2002; Ben Arfa et al., 2006). Exchanging the hydroxyl group of carvacrol with methyl ether affects its hydrophobicity, antimicrobial activity, and changes how 


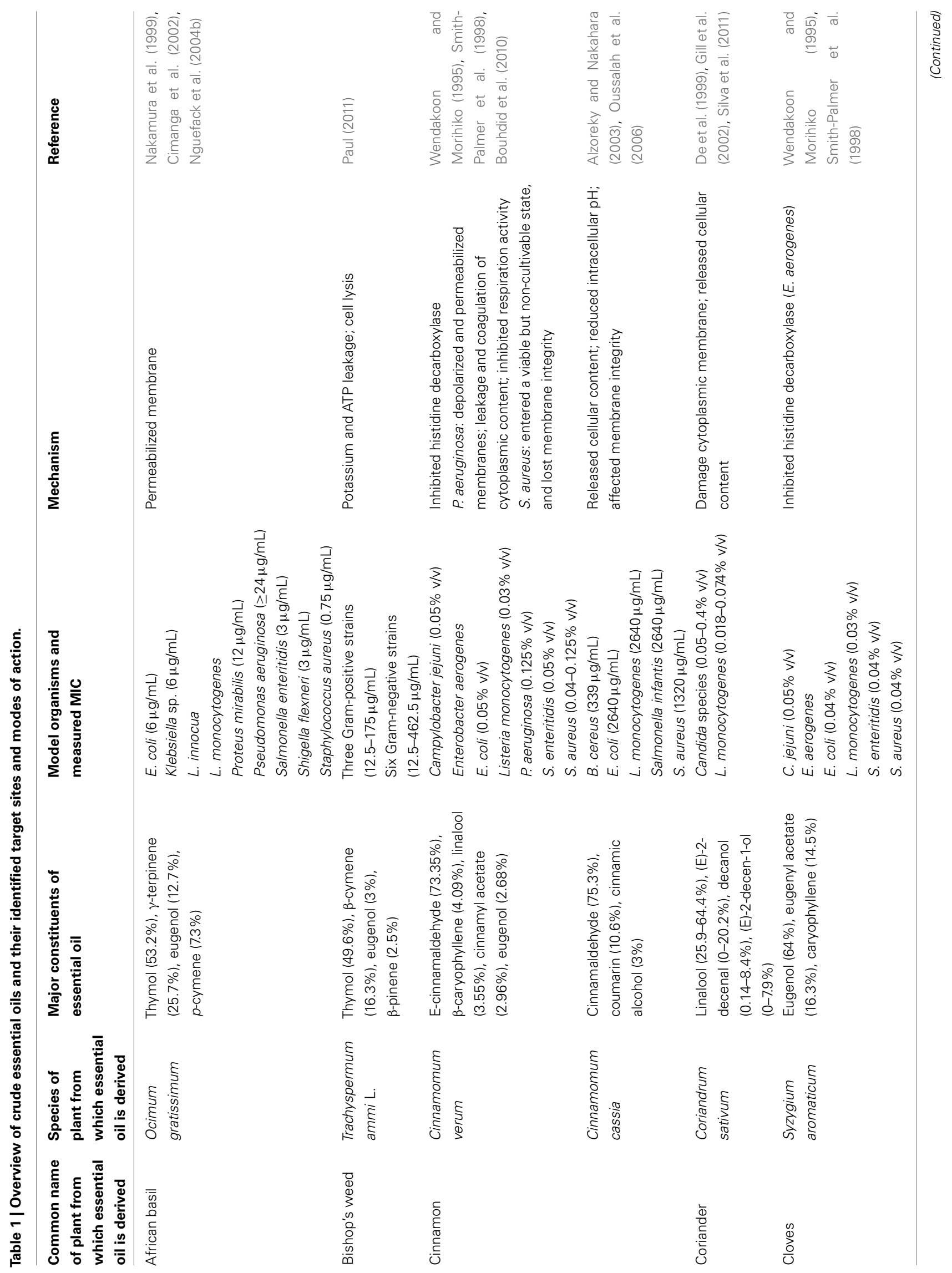




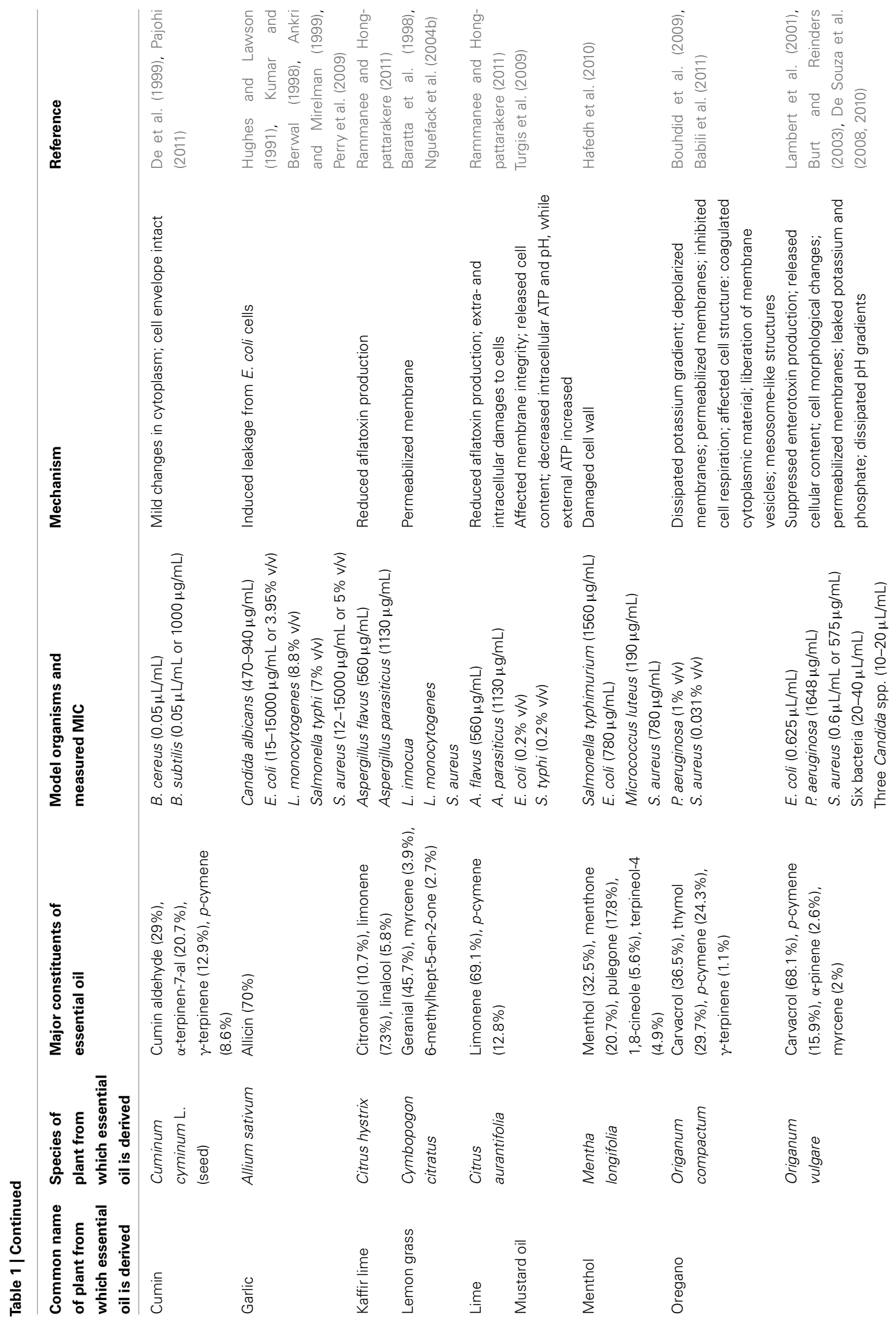



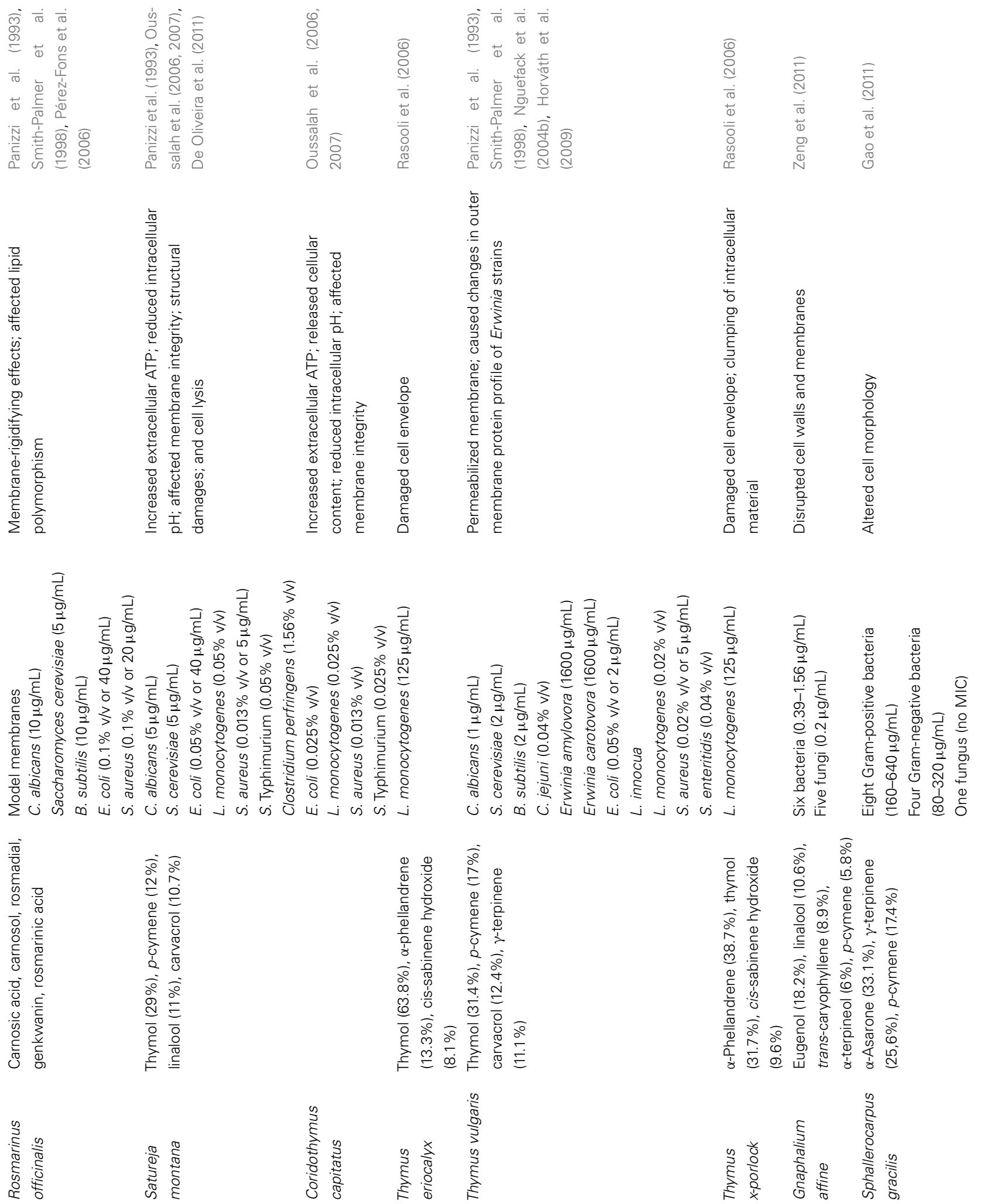

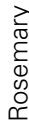

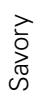

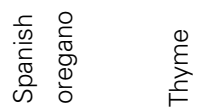




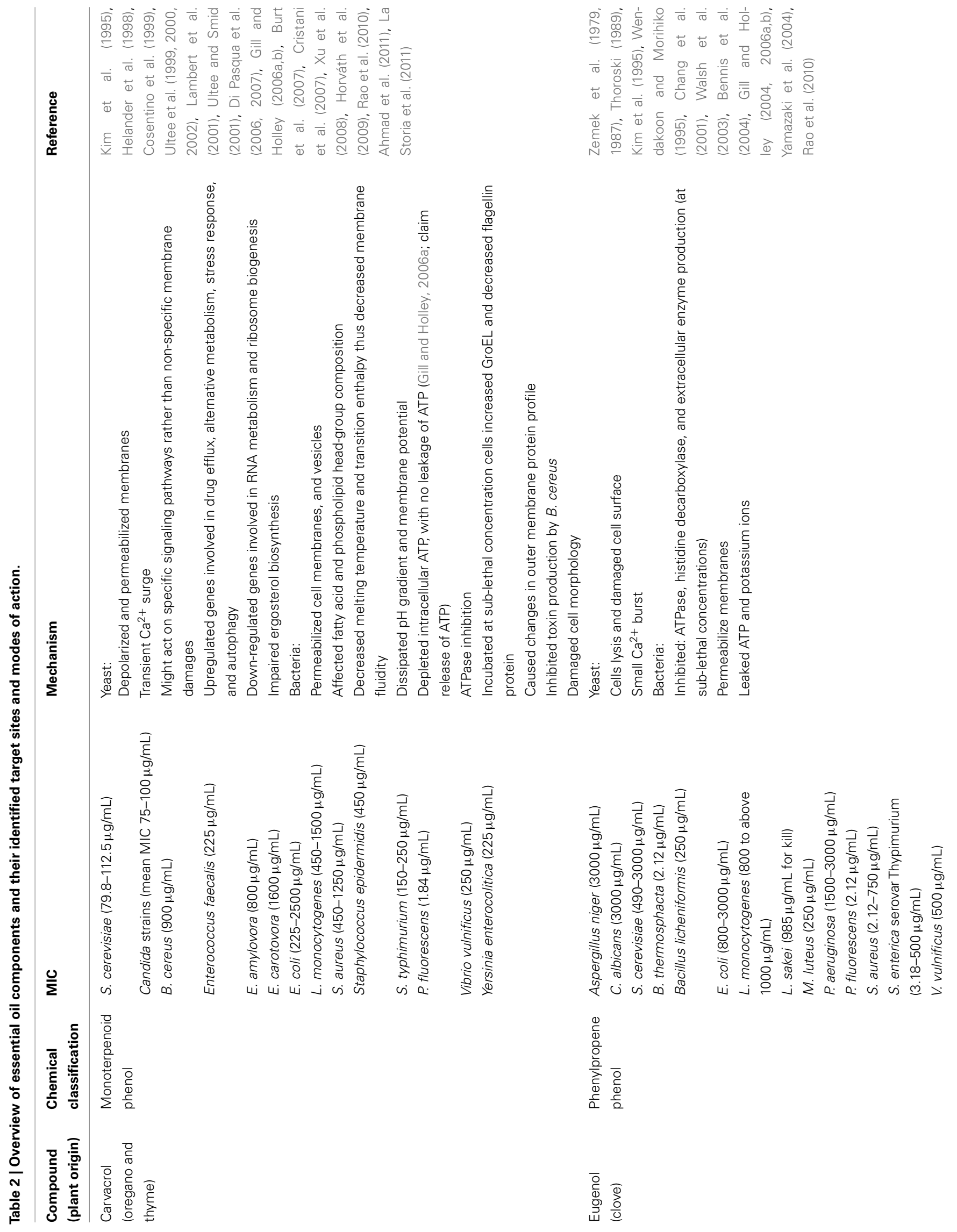



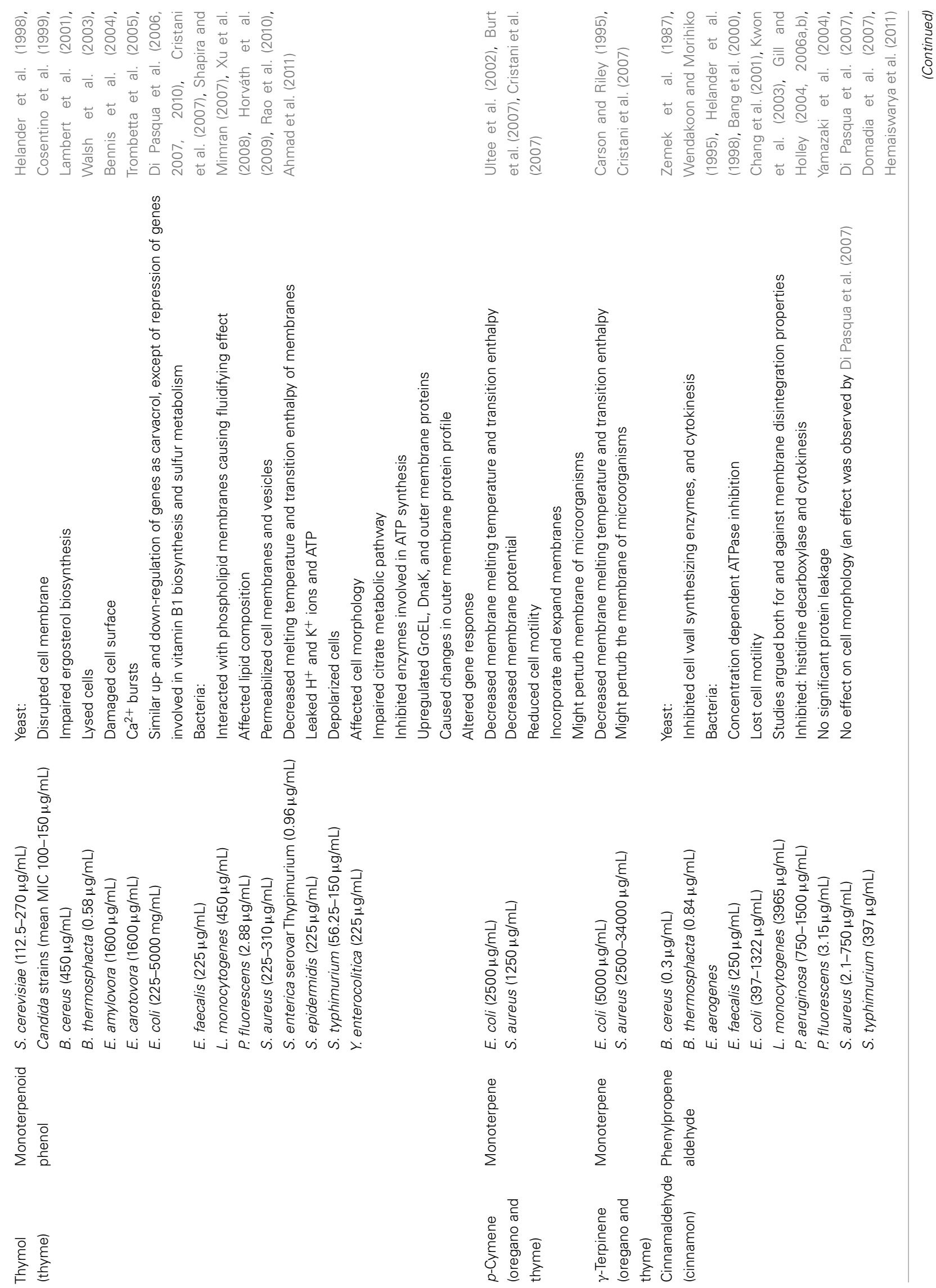

鼠 


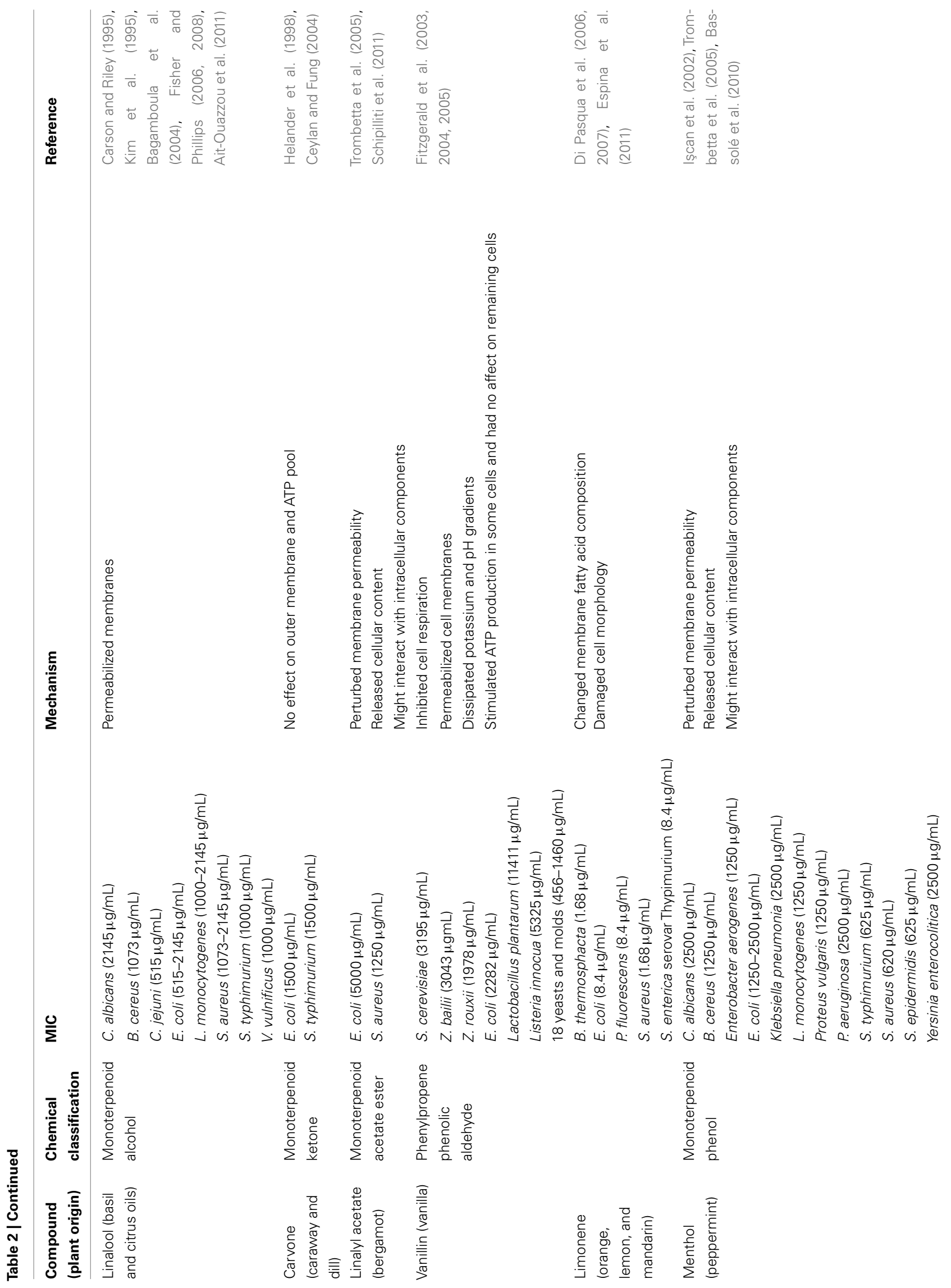



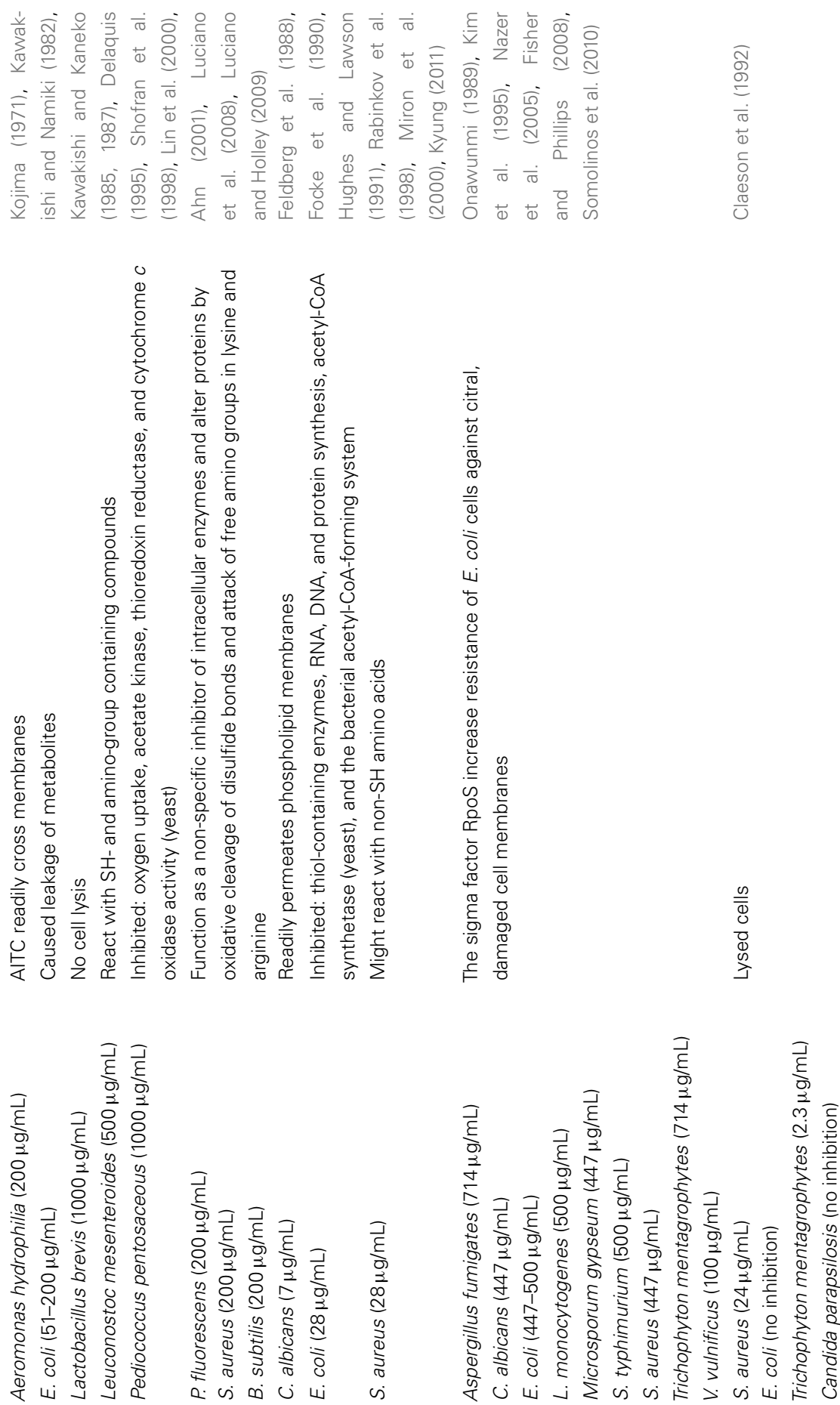

$\frac{3}{4}$
$\frac{1}{5}$
0
0
$\frac{1}{00}$
0
0
0
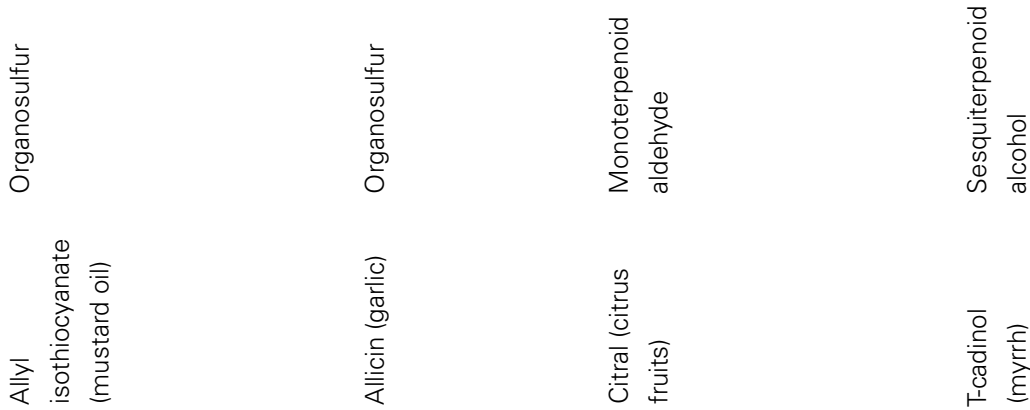

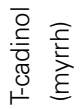




\section{Terpenes}

Monoterpenes<smiles>CC1=CCC2CC1C2(C)C</smiles><smiles>C=C(C)[C]1CC=C(C)CC1</smiles>

a-Pinene<smiles>C=C1CCC2(C(C)C)CC12</smiles>

Sabinene<smiles>Cc1ccc(C(C)C)cc1</smiles>

P-cymene $\quad \gamma$-Terpinene<smiles>CC1=CCC(C(C)C)=CC1</smiles>

Sesquiterpenes<smiles>C=C1CC/C=C(/C)CC[C@@H]2C(C)C[C@H]1C2C</smiles>

$\beta$-Caryophyllene

\section{Terpenoids}

\section{Monoterpenoids}<smiles>C=CC(C)(O)CCC=C(C)C</smiles>

Linalool<smiles>CC(C)=CCCC(C)CC=O</smiles>

Citronellal<smiles>Cc1ccc(C(C)C)c(O)c1</smiles>

Thymol<smiles>Cc1ccc(C(C)C)cc1O</smiles>

Carvacrol<smiles>C=C(C)C1CC=C(C)C(=O)C1</smiles>

Carvone<smiles>CC1(C)C2CCC1(C)C(O)C2</smiles>

Borneol

\section{Phenylpropanoids}<smiles>O=C/C=C/c1ccccc1</smiles><smiles>C=CCc1ccc(O)c(OC)c1</smiles>

Eugenol<smiles>COc1cc(C=O)ccc1O</smiles>

Vanillin<smiles>C=CCc1ccc2c(c1)OCO2</smiles>

Safrole

\section{Others}<smiles>C=CCN=C=S</smiles>

Allyl-isothiocyanate<smiles>C=CCS[S+]([O-])CC=C</smiles>

Allicin

FIGURE 1 | Chemical structures of selected essential oil constituents.

the molecule interacts with the membrane (Veldhuizen et al., 2006). Carvacrol's antimicrobial activity is comparable to that of 2 -amino- $p$-cymene, which indicates that the hydroxyl group is important, but not essential for carvacrol's activity (Veldhuizen et al., 2006). The antimicrobial activity of essential oils can often be correlated to its content of phenolic constituents (Aligiannis et al., 2001; Kalemba and Kunicka, 2003; Rhayour et al., 2003).

The terpenoids are a large group of antimicrobial compounds that are active against a broad spectrum of microorganisms, with the most active monoterpenoids identified so far being carvacrol and thymol. Dorman and Deans (2000) investigated the effect of many terpenoids against 25 different bacterial strains, and showed that all terpenoid compounds, except borneol and carvacrol methyl ester, exhibited a broad antimicrobial activity. The antimicrobial activity of carvacrol, thymol, linalool, and menthol were evaluated against Listeria monocytogenes, Enterobacter aerogenes, E. coli, and Pseudomonas aeruginosa. The most active compound was carvacrol followed by thymol with their highest MIC being 300 and $800 \mu \mathrm{g} / \mathrm{mL}$, respectively (Bassolé et al., 2010). These results confirm the high antimicrobial activity of 
a broad collection of terpenoids, and because their chemical structures are closely related to that of terpenes, the increased activity compared to terpenes can be attributed to the functional moieties.

\section{Thymol}

The mode of action of thymol, a phenolic monoterpenoid and one of the major constituents of thyme oil, has received much attention from researchers. Thymol is structurally very similar to carvacrol, having the hydroxyl group at a different position on the phenolic ring (Figure 1). The antimicrobial action of phenolic compounds, such as thymol and carvacrol, are expected to cause structural and functional damages to the cytoplasmic membrane (Sikkema et al., 1995). The primary mode of antibacterial action of thymol is not fully known, but is believed to involve outerand inner membrane disruption, and interaction with membrane proteins and intracellular targets.

Studies have shown that thymol interacts with cell membranes. The interaction affects membrane permeability, and this has been documented by loss of membrane potential, cellular uptake of ethidium bromide, and leakage of potassium ions, ATP, and carboxyfluorescein (Helander et al., 1998; Lambert et al., 2001; Walsh et al., 2003; Xu et al., 2008). Although the protective properties of lipopolysaccharide (LPS) against thymol had been confirmed using random transposon-insertion mutants, treatment of E. coli cells with thymol caused release of LPS and disruption of the outer membrane (Helander et al., 1998; Shapira and Mimran, 2007). The outer membrane disruption could not be prevented by addition of magnesium, suggesting that thymol did not disrupt the membrane by chelating cations (Helander et al., 1998). Thymol integrates at the polar head-group region of a lipid bilayer causing alterations to the cell membrane, which at low concentrations induce adaptational changes in the membrane lipid profile in order to compensate for thymol's fluidifying effects and to maintain the membrane function and structure (Turina et al., 2006; Di Pasqua et al., 2007).

In addition to interacting with membrane phospholipids, evidence has accumulated that documents thymol's interaction with membrane proteins and intracellular targets, which hinder cell recovery after temporary exposure. The ability of thymol to interact with proteins was examined using the protein bovine serum albumin (BSA) and the organic compound deferoxamine, which is also rich in amine groups but otherwise known for its $\mathrm{Fe}^{3+}$ chelating properties. These compounds react similarly to that of amine groups in bacterial membrane proteins (Juven et al., 1994). Based on the antimicrobial activity of thymol in the absence and presence of the thymol-inhibiting deferoxamine or BSA, Juven et al. (1994) hypothesized that thymol forms a complex with membrane-bound or periplasmic proteins by means of hydrogen bonds and hydrophobic interactions. Interaction with membrane proteins was further supported by Di Pasqua et al. (2010) who exposed Salmonella enterica to sub-lethal concentrations of thymol, and observed accumulation of misfolded outer membrane proteins and upregulation of genes involved in synthesis of outer membrane proteins. Contrarily, down-regulation of outer membrane proteins was shown in Erwinia spp. (Horváth et al., 2009). Upon exposure to thymol, S. enterica upregulated production of the chaperon proteins Heat Shock Protein 60 (GroEL), and Heat Shock Protein 70 (DnaK), which are key proteins in the protection against thermal stress and misfolding of proteins (Di Pasqua et al., 2010; Hartl et al., 2011). Thymol also impaired the citrate metabolic pathway and affected many enzymes directly or indirectly involved in the synthesis of ATP (Di Pasqua et al., 2010). Thymol's intracellular action indicates that it affects important energy-generating processes, which lower a cells' ability to recover after exposure to thymol.

The mode of action of thymol against yeast and fungi has been sparsely investigated, but studies point to interactions with the cell envelope and intracellular targets. Thymol disrupted vesicles and cell membranes, and impaired ergosterol biosynthesis in Candida strains, which consequently affected cell membrane integrity because ergosterol regulates membrane fluidity and asymmetry similarly to cholesterol in animal cells (Ghannoum and Rice, 1999; Cristani et al., 2007; Ahmad et al., 2011). Interestingly, thymol induced cell lysis and only altered the cell structure of proliferating $S$. cerevisiae cells, indicating the effect of thymol depends on cell proliferation (Bennis et al., 2004). Contrary to this, Rao et al. (2010) proposed that thymol activates specific signaling pathways in yeast, rather than causing non-specific lesion of membranes. This proposal was based on the observation that thymol caused cytosolic $\mathrm{Ca}^{2+}$ bursts and transcription responses similar to $\mathrm{Ca}^{2+}$ stress and nutrient starvation (Rao et al., 2010).

\section{Carvacrol}

Carvacrol is a phenolic monoterpenoid and a major constituent of oregano. Together with its closely related isomer thymol, it is one of the most extensively studied essential oil constituents. The antimicrobial effect of carvacrol is expected to be similar to that of thymol, causing structural and functional damages to the cell membrane (Sikkema et al., 1995). The primary mode of action of carvacrol is its ability to position in the membrane where it increase permeability, however, other more specific actions may be important and will be discussed.

Carvacrol has been demonstrated to affect the outer membrane of Gram-negative bacteria (La Storia et al., 2011). Disintegration of the outer membrane caused release of LPS from Gram-negative bacteria (Helander et al., 1998). Although carvacrol affects the outer membrane, its site of action is thought to be the cytoplasmic membrane, resulting in passive transport of ions across the membrane. Carvacrol has a hydroxyl group that has been proposed to function as a transmembrane carrier of monovalent cations across the membrane, carrying $\mathrm{H}^{+}$into the cell cytoplasm and transporting $\mathrm{K}^{+}$back out (Ultee et al., 2002; Ben Arfa et al., 2006). However, Veldhuizen et al. (2006) found the hydroxyl group of carvacrol not to be essential for antimicrobial activity, and proposed that although the transmembrane proton carrier mechanism plays a role in the antimicrobial activity, the relatively high activity of a non-hydroxyl compound ruled it out as the main mode of action of carvacrol.

The evidences for the membrane as carvacrol's site of action are many, and the results suggest that the mode of action of carvacrol is to increase fluidity and permeability of membranes. It has been proposed that cells exposed to carvacrol change the fatty acid composition of the membrane as an adaptation mechanism 
to maintain optimal membrane structure and function because of carvacrol's effect on fluidity (Ultee et al., 2000; Di Pasqua et al., 2006, 2007). It is well established that increased membrane fluidity enhances the permeability of membranes (Nikaido, 1994). Membrane permeabilization by carvacrol has been confirmed by monitoring the efflux of $\mathrm{H}^{+}, \mathrm{K}^{+}$, carboxyfluorescein, and ATP, and the influx of nucleic acid stains (Helander et al., 1998; Ultee et al., 1999; Lambert et al., 2001; Cristani et al., 2007; Xu et al., 2008).

Besides the interaction with membranes, carvacrol has been proposed to interact with membrane proteins and periplasmic enzymes (Juven et al., 1994), but the evidence for this is limited. The only example used isolated bacterial membranes with ATPase activity as the indicator for direct molecular binding of carvacrol in an assay with excess amounts of ATP added (Gill and Holley, 2006b). Carvacrol has also been proposed to have intracellular targets, but the studies documenting this are few and do not identify the possible intracellular targets. Inhibitory concentrations of carvacrol caused over-expression of outer membrane proteins in Erwinia amylovora cells (Horváth et al., 2009), indicating that carvacrol possibly affect outer membrane protein folding or insertion. In another study, E. coli cells grown in the presence of sub-lethal concentration of carvacrol produced significant amounts of GroEL, indicating that protein folding was affected. Furthermore, it inhibited the synthesis of flagellin, which caused new cells to be without flagella (Burt et al., 2007). Cells that had flagella exhibited decreased motility at increasing carvacrol concentration, indicating that carvacrol disrupts the membrane potential and thereby the proton motive force needed to drive flagellar movement (Gabel and Berg, 2003; Burt et al., 2007).

The mechanism of antifungal activity of carvacrol resembles that of thymol, showing disruption of $\mathrm{Ca}^{2+}$ and $\mathrm{H}^{+}$homeostasis, up- and down-regulation of gene transcription similar to $\mathrm{Ca}^{2+}$ stress and nutrient starvation (Rao et al., 2010), disruption of membrane integrity and impairment of ergosterol biosynthesis in Candida strains (Ahmad et al., 2011).

\section{PHENYLPROPENES}

Phenylpropenes constitute a subfamily among the various groups of organic compounds called phenylpropanoids that are synthesized from the amino acid precursor phenylalanine in plants. Phenylpropanoids have their name from the six-carbon aromatic phenol group and the three-carbon propene tail of cinnamic acid, produced in the first step of phenylpropanoid biosynthesis. The phenylpropenes constitute a relatively small part of essential oils, and those that have been most thoroughly studied are eugenol, isoeugenol, vanillin, safrole, and cinnamaldehyde (Figure 1).

Comparison of molecules that are chemically similar to eugenol and isoeugenol indicated that the free hydroxyl groups are important for their activity against bacteria, but not yeast (Laekeman et al., 1990). Some of isoeugenol's activity might be attributed to the double bond in the $\alpha, \beta$ positions of the side chain, and a methyl group in the $\gamma$ position (Jung and Fahey, 1983). Furthermore, the antimicrobial activity of phenylpropenes depends on the kind and number of substituents on the aromatic ring, selected microbial strains, and the experimental test parameters such as choice of growth medium, temperature, etc. (Pauli and Kubeczka, 2010).
The antibacterial activity of eugenol was evaluated against 25 different bacterial strains of which only one strain was not inhibited (Dorman and Deans, 2000). Isoeugenol and eugenol showed pronounced inhibition activity against yeasts and 6 out of 10 Gram-positive and Gram-negative bacteria at $1000 \mu \mathrm{g} / \mathrm{mL}$ (Laekeman et al., 1990). The antimicrobial properties of isoeugenol appear more potent than eugenol, as lower MIC values are found against a variety of bacteria, yeast, and molds (Zemek et al., 1979, 1987). Interestingly, isoeugenol and eugenol have higher antimicrobial activity against Gram-negative bacteria, yeasts, and molds than Gram-positive bacteria (Mygind, unpublished). This is unusual for essential oil constituents because they normally are more effective against Gram-positive bacteria.

Cinnamaldehyde appears less potent than eugenol. In a study of L. monocytogenes and Lactobacillus sakei, 3965 and $66080 \mu \mathrm{g} / \mathrm{mL}$ of cinnamaldehyde, but only 821 and $985 \mu \mathrm{g} / \mathrm{mL}$ of eugenol were required to obtain a bactericidal effect (Gill and Holley, 2004). However, when tested against E. coli and Salmonella typhimurium, the antimicrobial activity of cinnamaldehyde equals that of the potent monoterpenoids thymol and carvacrol (Helander et al., 1998). Another phenylpropene, vanillin, inhibits a range of yeasts, molds, and bacteria (Fitzgerald et al., 2003, 2004, 2005; Rupasinghe et al., 2006). It should be noted that some yeasts were able to convert sub-lethal concentrations of vanillin into non-inhibitory compounds (Fitzgerald et al., 2003).

\section{Eugenol}

Eugenol is a major constituent in clove essential oil, and its antimicrobial activity is linked to its ability to permeabilize the cell membrane and interact with proteins. Eugenol's action on membranes occurs mainly by a non-specific permeabilization. The non-specific permeabilization of the cytoplasmic membrane by eugenol has been demonstrated in various studies as increased transport of potassium and ATP out of the cells (Walsh et al., 2003; Gill and Holley, 2006a; Hemaiswarya and Doble, 2009). Eugenol induced minor changes in the fatty acid profile of Pseudomonas fluorescens, E. coli, Brochotrix thermosphacta, S. enterica, and S. aureus, and cell damages to E. coli and B. thermosphacta cells (Di Pasqua et al., 2006, 2007).

The hydroxyl group of eugenol is thought to bind to and affect the properties of proteins, thereby contributing to eugenol's inhibitory effect at sub-lethal concentrations. Consistent with this, eugenol has proven to inhibit the activity of the following enzymes: ATPase, histidine decarboxylase, amylase, and protease (Thoroski, 1989; Wendakoon and Morihiko, 1995; Gill and Holley, 2006b). Inhibition of the ATPase may be important for cell killing at high eugenol concentrations because energy generation needed for cell recovery is impaired (Gill and Holley, 2006b).

The antifungal mode of action of eugenol needs further investigation, but it is known to depend on cell proliferation. Eugenol treatment altered cell membrane and cell wall structures of proliferating $S$. cerevisiae cells resulting in the release of cellular content (Bennis et al., 2004).

\section{Cinnamaldehyde}

Aldehyde groups are reactive and have the ability to cross-link covalently with DNA and proteins through amine groups, thereby 
interfering with their normal function (Feron et al., 1991). However, the mode of action of cinnamaldehyde, a phenylpropene aldehyde, is inconclusive. At least three things are believed to occur: At low concentrations, cinnamaldehyde inhibits different enzymes involved in cytokinesis or less important cell functions. At higher but sub-lethal concentrations, it acts as an ATPase inhibitor, and at lethal concentrations it perturbs cell membrane. Cinnamaldehyde was suggested to inhibit cytokinesis as a mode of action on $B$. cereus because cells could not separate although septa were present after division (Kwon et al., 2003). It has been established that cinnamaldehyde binds to the FtsZ protein, inhibiting its GTP dependent polymerization and thereby preventing cell division (Domadia et al., 2007; Hemaiswarya et al., 2011). The FtsZ protein is an attractive target for antimicrobial therapies as it is evolutionary distant from eukaryotic tubulin, and the predicted interaction of $\mathrm{H} 2$ and $\mathrm{H} 3$ of cinnamaldehyde with G295 and V208 of FtsZ, respectively, is conserved among FtsZ proteins from several species (Domadia et al., 2007; Hemaiswarya et al., 2011). Other enzymes, e.g., the histidine decarboxylase, is also inhibited by cinnamaldehyde (Wendakoon and Morihiko, 1995).

At sub-lethal concentrations, cinnamaldehyde gains access to the periplasm and inhibits the activity of transmembrane ATPase. Sub-lethal concentrations of cinnamaldehyde did not affect the integrity of the outer membrane of E. coli, but it inhibited growth and bioluminescence of Photobacterium leiognathi, indicating that cinnamaldehyde does gain access to the periplasm and possibly also the cytoplasm (Helander et al., 1998). The ability of cinnamaldehyde to access the periplasm was confirmed by demonstrating a decrease in ATPase activity of isolated cell membranes at increasing concentrations of cinnamaldehyde (13.6-1362 $\mu \mathrm{g} / \mathrm{mL}$; Gill and Holley, 2006a,b). ATPase inhibition was, however, suggested not to be the primary cause of cell death because the concentration required to inhibit the ATPase also resulted in membrane disruption of E. coli cells (681-1362 $\mu \mathrm{g} / \mathrm{mL}$; Gill and Holley, 2006a).

Many studies have demonstrated that cinnamaldehyde interacts with the cell membrane, but it is not yet clear how it perturbs membranes. It is not a general mode of action of cinnamaldehyde to disrupt membranes as illustrated by Di Pasqua et al. (2007). Cinnamaldehyde altered the membrane lipid profile with large increases in saturated fatty acids, yielding a more rigid membrane probably compensating for a fluidifying effect of cinnamaldehyde, and cell structure of E. coli, S. enterica, P. fluorescens, and B. thermosphacta, while only $S$. aureus demonstrated disintegration of the cell envelope (Di Pasqua et al., 2006, 2007). Cinnamomum verum essential oil (73\% cinnamaldehyde) caused membrane depolarization, loss of membrane integrity, reduced respiratory activity, and coagulation of cytoplasmic material of P. aeruginosa, while exposure of $S$. aureus cells caused them to enter a viable but non-cultivable state (Bouhdid et al., 2010).

Among fungi, the primary mode of action of cinnamaldehyde has also been proposed to be inhibition of cell division. This was proposed because cinnamaldehyde inhibited the cell wall synthesizing enzymes in S. cerevisiae by functioning as a non-competitive inhibitor of $\beta$-(1,3)-glucan synthase and a mixed inhibitor of chitin synthase isozymes (Bang et al., 2000).

\section{Vanillin}

The mode of action of the phenylpropene phenolic aldehyde vanillin is not well understood, but it has been proposed to function as a membrane active compound that might have intracellular targets.

The proposed membrane and protein interactions of vanillin are based on one study. Vanillin inhibited respiration of E. coli and Listeria innocua cells, and disrupt the potassium and $\mathrm{pH}$ homeostasis of Lactobacillus plantarum cells (Fitzgerald et al., 2004). Propidium iodide staining demonstrated that treatment with vanillin disrupted membrane integrity of only a sub-population of cells and it was proposed that although vanillin primarily is a membrane active compound, it may also have intracellular target sites (Fitzgerald et al., 2005).

Not much is known about vanillin's mechanism of antifungal activity, but it has been suggested that the aldehyde moiety of vanillin plays an important role in its antifungal activity. The rationale for this is that $S$. cerevisiae convert vanillin into vanillic acid and vanillyl alcohol, which possess no antimicrobial activity, confirming the key-role of the aldehyde moiety (Feron et al., 1991; Fitzgerald et al., 2005).

\section{OTHER ESSENTIAL OIL CONSTITUENTS}

Essential oils contain a number of different degradation products originating from unsaturated fatty acids, lactones, terpenes, glycosides, and sulfur- and nitrogen-containing compounds (Caballero et al., 2003). Two examples of sulfur- and nitrogen-containing compounds with known antimicrobial activity are allicin and allyl isothiocyanate (AITC).

Allicin (diallyl thiosulfinate) is found in garlic and plays an important role in plant defense (Ankri and Mirelman, 1999). Inside the garlic cloves, the amino acid cysteine is converted to alliin ( $S$-allyl-L-cystein- $S$-oxide), a known sulfoxide with no antimicrobial activity (Block, 1992; Ankri and Mirelman, 1999). Conversion of alliin to the antimicrobial allicin requires the enzyme alliinase. Studies suggest that alliin and alliinase are located in two different compartments (Ankri and Mirelman, 1999), and when garlic cloves are crushed, alliinase comes into contact with alliin and produces allicin (Ankri and Mirelman, 1999). Allicin has a pungent smell of garlic and exhibits antibacterial, antifungal, antiparasitic, and antiviral properties (Kyung, 2011). Allicin is equally effective against Gram-negative and Gram-positive bacteria (Cavallito and Bailey, 1944). Allicin is bactericidal with $\mathrm{LD}_{50}$ values against different bacteria ranging between 3 and more than $100 \mu \mathrm{g} / \mathrm{mL}$, while a bacteriostatic effect was observed at much lower concentrations reflected in MIC values for fungal pathogens were in the range 0.15-1.5 $\mu \mathrm{g} / \mathrm{mL}$ (Ankri and Mirelman, 1999). Although allicin shows great potential as a food preservative when evaluated in vitro, conflicting results have been obtained in food matrixes (Kyung, 2011).

Isothiocyanates, also known as mustard oils, are common essential oil constituents from plants belonging to the mustard family (Brassicaceae), such as mustard, broccoli, horseradish, and turnips (Nielsen and Rios, 2000). Isothiocyanates arise in plants as a result of enzymatic cleavage of released glucosinolates from intracellular compartments by membrane-bound myrosinase upon damage to the plant (Delaquis, 1995). Myrosinase 
promotes hydrolysis and intramolecular rearrangement of intermediates, resulting in the three main groups of substances: nitriles, thiocyanates, and isothiocyanates (Zhang and Talalay, 1994). The latter group includes the non-phenolic volatile AITC which can constitute close to $90 \%$ of the oil composition (Ward et al., 1998). Allyl isothiocyanate in vapor and liquid forms has demonstrated high bactericidal activity against various food spoilage microorganisms and food pathogens, including E. coli O157:H7 (Luciano and Holley, 2009), S. typhimurium, L. monocytogenes, and other aerobic Gram-negative spoilage bacteria (Delaquis, 1997), and a broad spectrum of fungi (Delaquis, 1997; Nielsen and Rios, 2000).

\section{Allicin}

The antimicrobial activity of allicin has been known since it was first isolated and studied by Cavallito and Bailey (1944), since then the mode of action of allicin have been elucidated in great detail. Allicin is shown to target intracellular enzymes by interacting with their free SH groups.

Allicin is readily transported across the cell membrane into the cytoplasm where it can exert its antimicrobial action. Garlic extract, with allicin as major component, induced no significant changes in E. coli and S. aureus cell morphology, supporting the hypothesis that allicin acts intracellularly (Perry et al., 2009). In another study, Miron et al. (2000) showed that allicin freely permeated phospholipid vesicles and reacted with encapsulated SH-containing molecules.

The antimicrobial activity of allicin is ascribed to its reactive chemical group that binds to and inhibits a broad-range of intracellular targets. Allicin's -S(O)-S- group reacts with $\mathrm{SH}$ groups of enzymes (Rabinkov et al., 1998). Allicin irreversibly inhibited the thiol-protease papain, $\mathrm{NADP}^{+}$-dependent alcohol dehydrogenase from Thermoanaerobium brockii, and a NAD ${ }^{+}$-dependent alcohol dehydrogenase from horse liver (Rabinkov et al., 1998). Interestingly, all three enzymes could be reactivated with thiolcontaining components like dithiothreitol, 2-mercaptoethanol, and glutathione (Rabinkov et al., 1998), demonstrating that the interaction leading to inhibition is reversible. Focke et al. (1990) also demonstrated reversible inhibition by specific binding of allicin to the enzymes involved in acetyl-CoA synthesis in bacteria, plants, yeasts, and mammals. Allicin only partially and transiently inhibited the DNA replication and protein synthesis in $S$. typhimurium, while RNA synthesis was reduced by more than $90 \%$ for at least $30 \mathrm{~min}$, suggesting RNA synthesis as the primary target of allicin (Feldberg et al., 1988). Collectively, these studies indicate that allicin is a non-specific inhibitor of many enzymes. Allicin could potentially be used in combination with other antimicrobials because it has inhibiting effects on RNA synthesis and thereby reduce or hinder cell protection mechanisms induced by other antimicrobials.

\section{Allyl isothiocyanate}

The mode of action behind AITC's antimicrobial activity is not yet fully understood, but since it might penetrate membranes and no single site of action has been described, it is generally regarded as a non-specific inhibitor of periplasmic or intracellular targets.

It is not yet clear if AITC rapidly crosses membranes and enters the cytoplasm of prokaryotic and eukaryotic cells, or if it has an effect on cell membranes. Ahn (2001) visualized the AITC-treated cells by transmission electron microscopy (TEM) and showed that AITC altered the internal cell structures without causing ATP leakage or cell wall damages to L. monocytogenes. However, it did reduce the internal levels of ATP, indicating that cellular energygenerating processes were affected. In contrast, another study showed that AITC caused cell membrane damages to E. coli and Salmonella Montevideo leading to leakage of cellular metabolites, but not cell lysis (Lin et al., 2000).

The mode of action of AITC is due to its chemical group. The central carbon atom of isothiocyanate $(\mathrm{R}-\mathrm{N}=\mathrm{C}=\mathrm{S})$ is highly electrophile and reacts readily, and under mild conditions with oxygen-, sulfur-, or nitrogen-centered nucleophiles resulting in carbamates, thiocarbamates, or thiourea derivatives, respectively (Zhang and Talalay, 1994; Verma, 2003). Inside a cell, AITC can react with glutathione, sulfites, amino acids, oligopeptides, proteins, and water (Kawakishi and Namiki, 1982; Kawakishi and Kaneko, 1985, 1987; Cejpek et al., 2000). AITC cleaves the cysteine disulfide bond in proteins through an oxidative process (Kawakishi and Namiki, 1982), but also attacks free amino groups and arginine residues (Kawakishi and Kaneko, 1987). The antimicrobial mode of action of AITC is thus related to its general inhibition of enzymes and alteration of proteins by oxidative cleavage of disulfide bonds (Delaquis, 1995; Luciano and Holley, 2009).

The action of AITC on yeast is not well understood and warrants more investigation. Allyl isothiocyanate stalls oxygen uptake of yeasts, and uncouples the oxidative phosphorylation through the inhibition of cytochrome c oxidase in the electron transport chain (Kojima, 1971). Due to its very general mode of action in prokaryotes, similar effects are likely observed in eukaryotes also.

\section{EXPERIMENTAL APPROACHES TO INVESTIGATE THE ANTIMICROBIAL MODE OF ACTION}

The diversity of essential oil constituents is enormous and presents a wide range of compounds. Some have low or no efficiency against microorganisms while others are potent antimicrobials. The majority of antimicrobial compounds found in essential oils are terpenoids and phenylpropenes with the most active being phenols, although some aldehydes and non-phenolic substances also present promising antimicrobial activity. The target site and mode of action of most essential oil components is still not well understood, especially in yeast. Commercial applications of essential oils would benefit from deeper insight into the mode of action behind individual compounds, as this could facilitate the exploitation of, e.g., synergistic combinations with more powerful antimicrobial properties.

Many different techniques have been applied to elucidate the mode of action of essential oils and their constituents. Here we will present and discuss the most common experimental approaches. After establishing the killing or inhibition activity of a compound, an array of experiments can be performed to identify how a compound interacts with the cell to cause the observed effects. In this context, it is important to distinguish between experiments that identify the target site from those that elucidate the mode of action. The site of action refers to the part of the cell which interacts with the compound, e.g., the cell membrane, cell wall, or intracellular proteins, enzymes, nucleic acids, or metabolites. The mode 
of action, however, yields more elaborate knowledge about the molecular mechanisms or intermolecular interactions behind the inhibition or killing effects. An overview of methods addressing the site or mode of action of antimicrobial compounds is provided in Table 3.

\section{LOCATING THE SITE OF ACTION}

High-resolution microscopy, such as electron microscopy or atomic force microscopy (AFM), can reveal the most extreme consequences of exposure to an antimicrobial compound, i.e., deformation of cells occurring from lysis or from damages to the cell wall. An advantage of TEM is that ultra-thin cross sections can reveal ultrastructural changes in the interior of the cell. Scanning electron microscopy (SEM) and AFM only image the cell surface. AFM has one important advantage over electron microscopy, in that it allows measurements in liquid under physiological conditions, avoiding difficult sample preparation and the artifacts associated herewith (Alessandrini and Facci, 2005). A limitation of both AFM and electron microscopy is, however, that specific cellular structures must be identified according to morphology unless some form of labeling can be applied. While antibodies conjugated to metal nanoparticles have been used with TEM in a few studies (Romero et al., 2010), no labeling techniques have been reported for SEM and AFM. It is, however, possible to combine AFM with optical microscopy and thus take advantage of the numerous options for fluorescent labeling of biomolecules.

An important site of action is the cell membrane, and indeed, many essential oil constituents have been proposed to act on the bacterial membrane. Interaction of antimicrobial compounds with the membrane can affect the transport of nutrients and ions, the membrane potential, and the overall permeability of the cell. These effects are investigated by measuring the efflux of intracellular ions like $\mathrm{K}^{+}$and $\mathrm{H}^{+}$(Ultee et al., 1999; Lambert et al., 2001). Efflux of small ions is not necessarily indicative of complete loss of membrane function, and can be observed in viable cells where growth is inhibited because the cell uses energy for repair or survival rather than cell proliferation (Bouhdid et al., 2010). Effects on the cell membrane that lead to cell death is more accurately predicted by detecting the efflux of larger molecules like ATP or carboxyfluorescein diacetate (cFDA) after esterase reaction (Xu et al., 2008), or by influx of large polar organic DNA-binding stains like ethidium bromide (Lambert et al., 2001) and propidium iodide (Bouhdid et al., 2010). It should be pointed out that it is always good practice to validate the observed effects by combining several techniques. Monitoring the release of calcein encapsulated in membrane vesicles can for example be used as a complimentary technique to confirm the membrane as the site of action (Miron et al., 2000).

If no effects are observed on cell structure and membrane functionality, it is assumed that the site of action is intracellular. The target can be proteins and enzymes in general, or it can be essential cellular processes involved in biosynthesis or energy generation. An intracellular site of action can for example be determined by incorporation of radioactively labeled substrates used in particular biosynthesis pathways (Schneider et al., 2010). Lack of or decreased incorporation is then taken as an indication of the process being affected by the antimicrobial compound. For example, radiolabeled nucleotides or amino acids can be used to detect if DNA replication or protein synthesis takes place, respectively (Schneider et al., 2010).

Some compounds have multiple sites of action, and in that case it can be difficult to pinpoint which one is ultimately responsible for cell death. For example, a compound that affects membrane permeability will also affect the membrane potential and thereby energy generation by respiration. It is thus difficult to distinguish direct effects on energy-generating processes from the indirect effect a permeable membrane has on these processes. At sublethal concentrations, changes to the transcriptome and proteome during exposure can reveal how the cell responds to the compound, and upregulation of genes involved in certain metabolic or biosynthesis pathways can be indicative of which cell structures or processes that are affected (Burt et al., 2007; Rao et al., 2010).

\section{ELUCIDATING THE MODE OF ACTION}

The probably most comprehensive approach to investigate the mode of action of a particular compound is to perform random transposon mutagenesis in order to search for mutations that compensate for the antimicrobial effect of a particular compound. In this way, it is possible to identify the mode of action of compounds that interact very specifically with, e.g., a single enzyme or with particular proteins or lipids in the membrane (Shapira and Mimran, 2007; Van Hoang et al., 2011). The approach is, however, not suited for investigating antimicrobial compounds that act simultaneously on several components in the cell, as a single mutation is unlikely to facilitate compensation for the antimicrobial effect on the cell as a whole.

Antimicrobial compounds that act on the membrane can cause depolarization or increased permeability through various mechanisms. For example, some antimicrobial peptides form pores (Cotter et al., 2005; Fantner et al., 2010) while other compounds, such as certain essential oil constituents, have a fluidifying effect on the membrane (Trombetta et al., 2005; Cristani et al., 2007). Membrane properties like lipid packing can be investigated in membrane vesicles by LAURDAN staining combined with spectrofluorometry (Nielsen and Otzen, 2010), and membrane fluidity can be investigated directly in bacteria by differential scanning calorimetry (Trombetta et al., 2005) or fluorescence anisotropy measurements of DPH using a spectrofluorometer (Liao et al., 2010). AFM imaging has also in recent years allowed highresolution visualization of native membranes on a solid support. Structural changes resulting from integration of an antimicrobial compound into the membrane can thus be visualized directly (Brasseur et al., 2008), and the effect on membrane rigidity can be quantified by AFM force spectroscopy (Sullan et al., 2010). Functionalizing the AFM tip with the antimicrobial compound of interest furthermore allows investigation of interaction forces between the compound and its target. This approach was for example used to map binding events of vancomycin on the surface of bacteria and confirmed that binding occurred at the site of cell wall synthesis in dividing cells (Gilbert et al., 2007).

\section{ESSENTIAL OILS IN FOOD PRESERVATION}

Food-borne diseases are a growing public health problem worldwide. It is estimated that each year in the United States, 31 species of 
Table 3 | Overview of experimental approaches used to identify target sites and modes of action of antimicrobial compounds.

\section{Target site or mode of action}

Changes in cell morphology

Disruption of cytoplasmic membrane

Disruption of outer membrane in Gram-negative bacteria

Changes in membrane properties

\section{Experiment}

Scanning electron microscopy (SEM) visualizes the cell structure with sub-micron resolution.

Transmission electron microscopy (TEM) can visualize changes in cell morphology, damages to cell wall and cell membrane, and coagulation of intracellular content.

Atomic force microscopy (AFM) visualizes cells at nanometer resolution in liquid under physiological conditions, and can provide information about changes in cell topography and elasticity.

Cell lysis or release of cellular content can be detected spectrophotometrically at $260 \mathrm{~nm}$.

Measurement of potassium or phosphate leakage from the cells using ion-selective electrodes, atomic absorption spectroscopy, or flame photometry.

Measurement of ATP leakage from the cells using an assay based on luciferase activity quantified by bioluminescence.

Uptake of fluorescent DNA-binding stains, such as propidium iodide (PI), SYTO9, ethidium bromide (EB), and carboxyfluorescein diacetate (cFDA), using fluorescence microscopy or flow cytometry.

Leakage of the self-quenching dyes calcein or carboxyfluorescein encapsulated in phospholipid vesicles is as an increase in fluorescence intensity as the intravesicular concentration decreases. Changes in concentration gradients of ions across a cell membrane can be detected by fluorometry using bis-oxonol or $\mathrm{DiSC}_{3}(5)$, or by flow cytometry using bis-oxonol, $\mathrm{DiOC}_{2}$ (3), or BOX.

Damages to the outer membrane is detected by monitoring the uptake of the hydrophobic fluorescent probe.

1-N-phenyl---napthylamine (NPN) into the membrane using fluorescence microscopy.

Release of phospholipid and LPS from the outer membrane is detected by capillary gas chromatography and compared with an internal fatty acid standard. The release of proteins from the outer membrane is detected by a electrophoresis (SDS-PAGE) in which the protein profiles of cell-free supernatants of treated and untreated cells are compared.

Changes in the protein profile of the outer membrane can be measured by separating the proteins according to mass and labeling for detection by laser induced fluorescence.

Membrane expansion can be detected by relief of fluorescence self-quenching by the liposome probe octadecyl rhodamine $\beta$ chloride. Effects on membrane melting temperature, fluidity, and phase separation can be detected using differential scanning calorimetry, Fourier-transform infrared spectrometer, nuclear magnetic resonance, or small-angle X-ray diffraction.

\section{Reference}

Burt and Reinders (2003), Kwon et al. (2003), Bennis et al. (2004), Di Pasqua et al. (2007), Turgis et al. (2009), De Souza et al. (2010), Gao et al. (2011), Lv et al. (2011), Paul (2011) Claeson et al. (1992), Gustafson et al. (1998), Ahn (2001), Carson et al. (2002), Rasooli et al. (2006), Bouhdid et al. (2009, 2010), Fisher and Phillips (2009), De Oliveira et al. (2011), Pajohi (2011), Rammanee and Hongpattarakere (2011), Zeng et al. (2011)

Perry et al. (2009), Hafedh et al. (2010), La Storia et al. (2011)

Carson et al. (2002), Bennis et al. (2004), Turgis et al. (2009), De Souza et al. (2010), Lv et al. (2011), Paul (2011)

Lambert and Hammond (1973), Ultee et al. (1999), Cox et al. (2000), Lambert et al. (2001), Walsh et al. (2003), Fitzgerald et al. (2004), Shapira and Mimran (2007), Bouhdid et al. (2009, 2010)

Helander et al. (1998), Ultee et al. (1999, 2002), Ahn (2001), Fitzgerald et al. (2004), Gill and Holley (2004, 2006b), Fisher and Phillips (2009), Turgis et al. (2009), Sánchez et al. (2010), Paul (2011)

Cox et al. (2000), Lambert et al. (2001), Fitzgerald et al. (2004), Nguefack et al. (2004a), Gill and Holley (2006a), Paparella et al. (2008), Bouhdid et al. (2009, 2010), Somolinos et al. (2010), Ahmad et al. (2011), Ait-Ouazzou et al. (2011)

Cox et al. (2000), Miron et al. (2000), Trombetta et al. (2005), Cristani et al. (2007)

Ultee et al. (1999, 2002), Veldhuizen et al. (2006), Xu et al. (2008), Bouhdid et al. (2009, 2010), Fisher and Phillips (2009), Sánchez et al. (2010), Silva et al. (2011)

Helander et al. (1998), Fisher and Phillips (2009)

Helander et al. (1998)

Horváth et al. (2009)

Ultee et al. (2002)

Ultee et al. (2000), Trombetta et al. (2005), Pérez-Fons et al. (2006), Cristani et al. (2007) 
Table 3 | Continued

\section{Target site or mode of action}

Disruption of membrane potential Disruption of intracellular $\mathrm{pH}$ homeostasis

Disruption of intracellular

$\mathrm{Ca}^{2+}$

homeostasis

Disruption of cellular respiration

Complex reaction mechanism

Inhibition of particular enzymes cell division

Changes in transcriptome
Experiment

Changes in yeast cell's ergosterol biosynthesis can be evaluated by comparing the intracellular content of ergosterols of cells grown in the absence or presence of antimicrobials. The content of ergosterols in an intracellular extract can be calculated using data obtained from a spectrophotometrically scan of the extract between 240 and $300 \mathrm{~nm}$. Changes in concentration gradients of ions across a cell membrane can be detected either with a spectrofluorometer using bis-oxonol or $\mathrm{DiSC}_{3}(5)$, or by flow cytometry using bis-oxonol, $\mathrm{DiOC}_{2}(3)$, or BOX. 5-(and 6-)carboxyfluorescein diacetate succinimidyl ester (cFDA-SE) is readily taken up by bacteria and hydrolyzed by esterases to 5 -(and 6-)carboxyfluorescein succinimidyl ester (cFSE). The intracellular $\mathrm{pH}$ can then be determined from the ratio of the fluorescent signal of cFSE at the $\mathrm{pH}$-sensitive $490 \mathrm{~nm}$ and the $\mathrm{pH}$-insensitive $440 \mathrm{~nm}$. Intracellular $\mathrm{pH}$ is measured with $\mathrm{pH}$-sensitive fluorescent probes pHluorin (cytoplasmic) and BCECF AM (vacuoles).

Intracellular $\mathrm{Ca}^{2+}$ concentration is measured after transformation with a plasmid containing the gene for aequorin. Aequorin emits light upon binding $\mathrm{Ca}^{2+}$, and $\mathrm{Ca}^{2+}$ is thus quantified by measuring luminescence.

Disruption of the cellular respiration can be detected by oxygen consumption measured with oxygen electrodes or by reduction of the stain 5-cyano-2,3-ditolyl tetrazolium chloride (CTC), which is reduced by the electron transport chain to the insoluble and fluorescent formazan.

Reaction with thiol groups in a variety of targets can be monitored by complex formation with cysteine or glutathione as free $\mathrm{SH}$-group compounds. Complex formation is then detected with high performance liquid chromatography (HPLC), liquid chromatography coupled with mass spectroscopy (LC-MS), or NMR.

Competitive binding of thiol groups can also be tested by adding thiol-containing compounds, e.g., the protein bovine serum albumin (BSA) or the organic compound desferal to the growth medium and test if the antimicrobial effect can be relieved.

Inhibition of the cell wall synthesizing enzymes $\beta$-(1,3)-glucan synthase and chitin synthase have been monitored using the radioactive substrates UDP $\left[{ }^{14} \mathrm{C}\right]-\mathrm{Glu}$ and UDP[U- $\left.{ }^{14} \mathrm{C}\right]-\mathrm{GlcNAc}$ by a liquid scintillation counter.

Changes in enzyme activity of proteases, alcohol dehydrogenases, thioredoxin reductase, acetate kinase, decarboxylases, $\alpha$-amylase, subtilisin, acetyl-CoA-forming enzyme systems, and ATPase has been investigated, using techniques such as spectrophotometer, luminometer, HPLC, pH monitoring, liquid scintillation counter, and zone of proteolysis.

The effect on FtsZ assembly and hence on the cell division apparatus can be investigated using light scattering assay, GTP hydrolysis, TEM, isothermal titration calorimetry, saturation transfer difference NMR spectroscopy (STD NMR), and in silico molecular modeling.

Random mutation can be used to identify the role of a particular genes in resistance or susceptibility mechanisms. Transcriptional upand down-regulation can subsequently be detected for genes of interest using RT-qPCR, or for a large number of genes simultaneously using microarrays.

\section{Reference}

Ahmad et al. (2011)

Ultee et al. (1999, 2002), Veldhuizen et al. (2006), Xu et al. (2008), Bouhdid et al. (2009, 2010), Fisher and Phillips (2009), Sánchez et al. (2010), Silva et al. (2011)

Breeuwer et al. (1996), Ultee et al. (1999, 2002), Fitzgerald et al. (2004), Fisher and Phillips (2009), Turgis et al. (2009), Sánchez et al. (2010)

Rao et al. (2010)

Rao et al. (2010

Cox et al. (2000), Fitzgerald et al. (2004), Bouhdid et al. (2009, 2010)

Rabinkov et al. (1998), Miron et al. (2000), Luciano et al. (2008), Luciano and Holley (2009)

Juven et al. (1994)

Bang et al. (2000)

Thoroski (1989), Focke et al. (1990), Wendakoon and Morihiko (1995), Rabinkov et al. (1998), Gill and Holley (2006b), Luciano and Holley (2009)

Domadia et al. (2007), Hemaiswarya et al. (2011)

Somolinos et al. (2010), Shapira and Mimran (2007) 
Table 3 | Continued

\begin{tabular}{|c|c|c|}
\hline $\begin{array}{l}\text { Target site or } \\
\text { mode of action }\end{array}$ & Experiment & Reference \\
\hline & $\begin{array}{l}\text { Changes in RNA, DNA, and protein biosynthesis can be detected by } \\
\text { continuous incorporation of radioactive labeled uridine, thymidine, } \\
\text { and leucine, respectively. }\end{array}$ & Feldberg et al. (1988) \\
\hline \multirow[t]{2}{*}{$\begin{array}{l}\text { Changes in } \\
\text { proteome }\end{array}$} & $\begin{array}{l}\text { Expression of specific proteins can be determined by SDS-PAGE gel } \\
\text { electrophoresis and western blotting followed by identification of } \\
\text { peptide fragments by mass spectrometry. }\end{array}$ & Burt et al. (2007), Liu et al. (2010) \\
\hline & $\begin{array}{l}\text { Changes in a proteome profile can be detected by 2D-PAGE } \\
\text { electrophoresis separation followed by selection and excision of up- } \\
\text { or down-regulated protein-spots, which are then identified by mass } \\
\text { spectrometry. }\end{array}$ & Di Pasqua et al. (2010), Liu et al. (2010) \\
\hline $\begin{array}{l}\text { Changes in } \\
\text { toxin } \\
\text { production }\end{array}$ & $\begin{array}{l}\text { The effect on excreted toxin production can be measured using } \\
\text { enzyme linked immunosorbent assay (ELISA) and } \\
\text { spectrophotometric quantification. }\end{array}$ & Ultee and Smid (2001), De Souza et al. (2010) \\
\hline
\end{tabular}

pathogens cause 9.4 million cases of food-borne illnesses (Scallan et al., 2011). Successful control of food-borne pathogens requires the use of multiple preservation techniques in the manufacturing and storage of food products. A recent consumer trend toward preference for products with lower salt and sugar content presents an increased need for efficient food preservatives, as lowering the salt and sugar content would otherwise compromise the product's shelf-life (Zink, 1997). A wide range of preservatives are used to extend the shelf-life of a product by inhibiting microbial growth. However, an increasingly negative consumer perception of synthetic food additives has spurred an interest in finding natural alternatives to the traditional solutions (Zink, 1997). Although originally added to change or improve taste, the antimicrobial activity of essential oils makes them an attractive choice for substituting synthetic preservatives.

\section{PERSPECTIVES AND LIMITATIONS IN APPLICATION OF ESSENTIAL OILS IN FOOD}

A range of essential oil components have been accepted by the European Commission for their intended use as flavorings in food products. The registered flavorings are, e.g., linalool, thymol, eugenol, carvone, cinnamaldehyde, vanillin, carvacrol, citral, and limonene, all of which are considered to present no risk to the health of the consumer. The United States Food and Drug Administration (FDA) also classifies these substances as generally recognized as safe (GRAS). The crude essential oils classified as GRAS by FDA include amongst others clove, oregano, thyme, nutmeg, basil, mustard, and cinnamon. There are regulatory limitations on the accepted daily intake of essential oils or essential oil components, so before they can be used in food products, a daily intake survey should be available for evaluation by FDA.

Despite the demonstrated potential of essential oils and their constituents in vitro, their use as preservatives in food has been limited because high concentrations are needed to achieve sufficient antimicrobial activity. In many food products, the hydrophobic essential oil constituents are impaired by interactions with food matrix components, such as fat (Cava-Roda et al., 2010; Rattanachaikunsopon and Phumkhachorn, 2010), starch (Gutierrez et al., 2008), and proteins (Cerrutti and Alzamora, 1996; Kyung, 2011). Furthermore, the antimicrobial potency of essential oil constituents also depends on pH (Juven et al., 1994), temperature (Rattanachaikunsopon and Phumkhachorn, 2010), and the level of microbial contamination (Somolinos et al., 2010). Extrapolation of results from in vitro tests to food products is thus difficult at best, and a lower performance of the antimicrobial compound must be expected. For example, Cilantro oil had significant antibacterial activity at $0.018 \%$ in vitro, but when applied to a ham model, even $6 \%$ cilantro oil had no antimicrobial activity (Gill et al., 2002). Before being added to food products, it is therefore useful to investigate how essential oils or their constituents interact with food components in vitro. Food matrix interactions with the essential oils or their constituents can be investigated by measuring the growth of microorganisms in culture medium containing a range of concentrations of fat, protein, or starch as well as the antimicrobial compound of interest. Such experiments have been performed using a so-called food model media (Gutierrez et al., 2009), and can be used to provide quick answers to which kind of food products the compound in question can be used in.

The intense aroma of essential oils, even low concentrations, can cause negative organoleptic effects exceeding the threshold acceptable to consumers (Lv et al., 2011). Having to increase the concentration of essential oils to compensate for their interactions with food matrix components is therefore highly unfortunate and limits their application to spicy foods where the acceptable sensory threshold is relatively high. Different strategies can be used to circumvent this problem. One option is to use essential oils in active packaging rather than as an ingredient in the product itself. Essential oils can be encapsulated in polymers of edible and biodegradable coatings or sachets that provide a slow release to the food surface or to the headspace of packages of, e.g., fruit, meat, and fish (Pelissari et al., 2009; Sánchez-González et al., 2011). Sachets that release volatile essential oils into the headspace environment are simply placed within an enclosed food package (Ahvenainen, 2003). The advantage of incorporating volatile components of essential oils in films or edible coatings is that the diffusion rate of the agents away from the food product can be reduced, 
thereby maintaining the active compounds in the headspace or on the product surface for extended periods of time (Phillips and Laird, 2011; Sánchez-González et al., 2011). A way to minimize organoleptic effects of essential oils added to the matrix of a food product is to encapsulate essential oils into nanoemulsions. This approach increases the stability of volatile components, protecting them from interacting with the food matrix, and increases the antimicrobial activity due to increased passive cellular uptake (Donsí et al., 2011).

Lowering the concentration of essential oils without compromising their antimicrobial activity can also be obtained by applying them in combination with other antimicrobial compounds that provide a synergistic effect (Nguefack et al., 2012). Synergies are known to occur for essential oil combinations, and it is therefore a field with countless opportunities to find potent antimicrobial blends, which may be the key to implementing essential oils in food preservation without simultaneous organoleptic effects.

\section{SYNERGIES BETWEEN ESSENTIAL OIL COMPONENTS}

The interaction between antimicrobials in a combination can have three different outcomes, synergistic, additive, or antagonistic. Synergy occurs when a blend of two antimicrobial compounds has an antimicrobial activity that is greater than the sum of the individual components. An additive effect is obtained when the combination of antimicrobials has a combined effect equal to the sum of the individual compounds. Antagonism occurs when a blend of antimicrobial compounds has a combined effect less than when applied separately (Davidson and Parish, 1989; Burt, 2004).

The combined effect of a blend is analyzed by using measurements of the MIC to calculate the fractional inhibition concentration index $\left(\mathrm{FIC}_{\mathrm{Index}}\right)$ according to the formulas defined by (Davidson and Parish, 1989): $\mathrm{FIC}_{\mathrm{A}}=\mathrm{MIC}_{\mathrm{A}+\mathrm{B}} / \mathrm{MIC}_{\mathrm{A}}$, $\mathrm{FIC}_{\mathrm{B}}=\mathrm{MIC}_{\mathrm{B}+\mathrm{A}} / \mathrm{MIC}_{\mathrm{B}}, \mathrm{FIC}_{\text {Index }}=\mathrm{FIC}_{\mathrm{A}}+\mathrm{FIC}_{\mathrm{B}}$. The $\mathrm{MIC}_{\mathrm{A}+\mathrm{B}}$ value is the MIC of compound $\mathrm{A}$ in the presence of compound $\mathrm{B}$, and vice versa for $\mathrm{MIC}_{\mathrm{B}+\mathrm{A}}$. Calculating the FIC value for either substance A or B then requires determination of the MIC for the individual components. Theoretically, a FIC $_{\text {Index }}$ near 1 indicates additive interactions, while below 1 implicates synergy, and above 1 antagonism (Davidson and Parish, 1989). However, this definition has been replaced by a more general one where the FIC $_{\text {Index }}$ results are interpreted as synergistic if $\mathrm{FIC}_{\text {Index }}<0.5$, additive if $0.5<$ FIC $_{\text {Index }}<4$, or antagonistic if FIC $_{\text {Index }}>4$ (Odds, 2003).

The antimicrobial activity of a given essential oil may depend on only one or two of the major constituents that make up the oil. However, increasing amounts of evidence indicate that the inherent activity of essential oils may not rely exclusively on the ratio in which the main active constituents are present, but also interactions between these and minor constituents in the oils. Various synergistic antimicrobial activities have been reported for constituents or fractions of essential oils when tested in binary or ternary combinations (Delaquis et al., 2002; Pei et al., 2009; García-García et al., 2011; Nguefack et al., 2012). For example, García-García et al. (2011) found the most synergistic binary combination against L. innocua to be carvacrol and thymol, and the most active ternary combination to be carvacrol, thymol, and eugenol. Reports on greater antimicrobial activity of crude essential oils compared to blends of their major individual components suggests that trace components in the crude essential oils are critical to the activity and may have a synergistic effect (Marino et al., 2001; Delaquis et al., 2002; Burt, 2004; Koutsoudaki et al., 2005). In contrast to this, trace components may also cause antagonistic interactions, which were seen by comparing the antimicrobial effect of pure carvacrol to oregano oil where carvacrol is a major constituent. Pure carvacrol was 1500 times more effective than the crude essential oil (Rao et al., 2010). Among individual essential oil constituents, synergy has been observed for carvacrol and $p$-cymene on B. cereus (Ultee et al., 2002; Rattanachaikunsopon and Phumkhachorn, 2010). It appears that $p$-cymene swells bacterial cell membranes, probably enabling easier entrance of carvacrol into the cell membrane where it exerts its action (Ultee et al., 2002). Furthermore, Bassolé et al. (2010) showed that if linalool or menthol was combined with eugenol it showed the highest synergy, suggesting that a monoterpenoid phenol combined with a monoterpenoid alcohol is an effective combination.

Little is currently known about what governs synergy and antagonism among essential oil constituents. Four theoretical mechanisms of antimicrobial interactions produce synergy: (i) sequential inhibition several steps in a particular biochemical pathway, (ii) inhibition of enzymes that degrade of excrete antimicrobials, (iii) interaction of several antimicrobials with the cell wall, or (iv) interaction with the cell wall or membrane that leads to increased uptake of other antimicrobials (Davidson and Parish, 1989; Eliopoulos et al., 1996). Another possibility for synergistic effects could be that antimicrobials have different mode of actions, thereby attacking two different sites on or in the cell, which indirectly depend on each other. Even less is known about the cause antagonism, it is hypothesized to occur when: (i) combining bacteriostatic and bactericidal antimicrobials, (ii) antimicrobials have the same site of action, (iii) antimicrobials interact with each other (Davidson and Parish, 1989), Larson (1985) in Roller (2003). The hypothesized synergistic or antagonistic interactions are based on 15 year old results, and with the emergence of new techniques this field is likely to see some significant advances in our understanding of how antimicrobial compounds affect each other when acting in concert.

In practice, the knowledge needed to exploit synergistic combinations of essential oils in food products is (i) the site and mode of action of each essential oil constituent, and (ii) the mechanisms resulting in synergy or antagonism between several compounds, and (iii) how each compound interacts with food matrix components in a way that affects is antimicrobial properties. When the mechanistic details for synergistic interactions are better understood, it will be easier to exploit synergies using intelligent combinations of constituents to combat food spoilage microorganisms.

\section{OUTLOOK}

An attractive application of essential oils and their constituents is in food products to prolong the shelf-life of foods by limiting growth or survival of microorganisms. The organoleptic impact of essential oils and their components in food products currently limits their usage to spicy foods normally associated with herbs, spices, or seasonings. Synergistic interactions should therefore be 
exploited to lower the organoleptic impact and thereby facilitate the use in a broader range of products.

The lack of detailed knowledge about the mode of action of the individual essential oil constituents is also the underlying cause for our superficial understanding about what governs synergy and antagonism. Future research should thus explore the mode of action of individual essential oil constituents further, while also initiating systematic investigations into the mechanisms of synergy among different constituents. Many studies have investigated the site of action, while few proceed to reveal the mode of action. Furthermore, most work to date has focused on prokaryotes, and little is known about how essential oils interact with yeast and fungi. Regardless of the microorganism, future research into the mode of action will need a standardization of investigation methods, complementary experiments that validate results, and implementation of new techniques. Taking a systems biology approach to investigating the mode of action of antimicrobial compounds will no doubt further this field. Transcriptomic and proteomic analyses can identify pathways targeted by an antimicrobial, whereas nuclear magnetic resonance (NMR) spectroscopy, $\mathrm{X}$-ray crystallography, and computer modeling help identify key residues involved in the molecular interactions between target and the antimicrobial (Wang et al., 2006; Domadia et al., 2007; Liu et al., 2010; Schneider et al., 2010). Interactions with cell surface structures or cell membranes can be studied in detail by

\section{REFERENCES}

Ahmad, A., Khan, A., Akhtar, F., Yousuf, S., Xess, I., Khan, L., and Manzoor, N. (2011). Fungicidal activity of thymol and carvacrol by disrupting ergosterol biosynthesis and membrane integrity against Candida. Eur. J. Clin. Microbiol. Infect. Dis. 30, 41-50.

Ahmadifar, E., Falahatkar, B., and Akrami, R. (2011). Effects of dietary thymol-carvacrol on growth performance, hematological parameters and tissue composition of juvenile rainbow trout, Oncorhynchus mykiss. J. Appl. Ichthyol. 27, 1057-1060.

Ahn, E. S. (2001). Observation of bactericidal effect of allyl isothiocyanate on Listeria monocytogenes. Food Sci. Biotechnol. 10, 31-35.

Ahvenainen, R. (2003). Novel food Packaging Techniques. Cambridge: CRC Press, Woodhead Publishing Limited.

Ait-Ouazzou, A., Cherrat, L., Espina, L., Lorán, S., Rota, C., and Pagán, R. (2011). The antimicrobial activity of hydrophobic essential oil constituents acting alone or in combined processes of food preservation. Innov. Food Sci. Emerg. Technol. $12,320-329$.

Alessandrini, A., and Facci, P. (2005). AFM: a versatile tool in biophysics. Meas. Sci. Technol. 16, R65-R92.

Aligiannis, N., Kalpoutzakis, E., Mitaku, S., and Chinou, I. B. (2001). Composition and antimicrobial activity of the essential oils of two Origanum species. J. Agric. Food Chem. 49, 4168-4170.

Alzoreky, N. S., and Nakahara, K. (2003). Antibacterial activity of extracts from some edible plants commonly consumed in Asia. Int. J. Food Microbiol. 80, 223-230.

Ankri, S., and Mirelman, D. (1999). Antimicrobial properties of allicin from garlic. Microbes Infect. 1, 125-129.

Babili, F. E., Bouajila, J., Souchard, J. P., Bertrand, C., Bellvert, F., Fouraste, I., Moulis, C., and Valentin, A. (2011). Oregano: chemical analysis and evaluation of its antimalarial, antioxidant, and cytotoxic activities. J. Food Sci. 76, 512-518.

Bagamboula, C. F., Uyttendaele, M., and Debevere, J. (2004). Inhibitory effect of thyme and basil essential oils, carvacrol, thymol, estragol, linalool and p-cymene towards Shigella sonnei and S. flexneri. Food Microbiol. $21,33-42$.

Bang, K. H., Lee, D. W., Park, H. M., and Rhee, Y. H. (2000). Inhibition of fungal cell wall synthesizing enzymes by trans-cinnamaldehyde. Biosci. Biotechnol. Biochem. 64, 1061-1063.

Baratta, M. T., Dorman, H. J. D., Deans, S. G., Figueiredo, A. C., Barroso, J. G., and Ruberto, G. (1998). Antimicrobial and antioxidant properties of some commercial essential oils. Flavour Fragr J. 13, 235-244.

AFM force spectroscopy (Brasseur et al., 2008; Dufrêne, 2008). These techniques provide valuable information about an antimicrobial's specific intracellular targets, the structural nature of interaction, and what governs susceptibility, adaptation, and resistance mechanisms (Schneider et al., 2010).

Synergistic blends that have commercial interest must be evaluated under the relevant environmental conditions which reflect the food matrixes to which they should be applied, as interactions with food matrix ingredients could decrease their activity. Investigating the molecular interactions behind the inhibition of food matrix ingredients opens an entirely different research direction, which focuses on formulating essential oils in foods with the aim to minimize organoleptic effects without compromising the antimicrobial properties. Encapsulation and controlled/sustained release of potent synergistic combinations could potentially reduce the organoleptic impact and simultaneously increase the antimicrobial potency if the encapsulation material facilitates close interaction with the microorganisms. New strategies for nanoencapsulation may thus provide an interesting platform for this research avenue in the future.

\section{ACKNOWLEDGMENTS}

We acknowledge financial support from the Danish Agency for Science, Technology and Innovation under the Industry $\mathrm{PhD}$ program, and also from the Carlsberg Foundation.

Bassolé, I. H. N., Lamien-Meda, A., Bayala, B., Tirogo, S., Franz, C., Novak, J., Nebié, R. C., and Dicko, M. H. (2010). Composition and antimicrobial activities of Lippia multiflora Moldenke, Mentha x piperita $\mathrm{L}$. and Ocimum basilicum L. essential oils and their major monoterpene alcohols alone and in combination. Molecules 15, 7825-7839.

Ben Arfa, A., Combes, S., PreziosiBelloy, L., Gontard, N., and Chalier, P. (2006). Antimicrobial activity of carvacrol related to its chemical structure. Lett. Appl. Microbiol. 43, 149-154.

Bennis, S., Chami, F., Chami, N., Bouchikhi, T., and Remmal, A. (2004). Surface alteration of Saccharomyces cerevisiae induced by thymol and eugenol. Lett. Appl. Microbiol. 38, 454-458.

Block, E. (1992). The organosulfur chemistry of the genus Allium implications for the organic chemistry of sulfur. Angew. Chem. Int. Ed. Engl. 31, 1135-1178.

Bouhdid, S., Abrini, J., Amensour, M., Zhiri, A., Espuny, M. J., and Manresa, A. (2010). Functional and ultrastructural changes in Pseudomonas aeruginosa and Staphylococcus aureus cells induced by Cinnamomum verum essential oil. J. Appl. Microbiol. 109, 1139-1149.

Bouhdid, S., Abrini, J., Zhiri, A., Espuny, M. J., and Manresa, A.
(2009). Investigation of functional and morphological changes in Pseudomonas aeruginosa and Staphylococcus aureus cells induced by Origanum compactum essential oil. J. Appl. Microbiol. 106, 1558-1568.

Brasseur, R., Deleu, M., MingeotLeclercq, M. P., Francius, G., and Dufrene, Y. F. (2008). Probing peptide-membrane interactions using AFM. Surf. Interface Anal. 40, 151-156.

Breeuwer, P., Drocourt, J. L., Rombouts, F. M., and Abee, T. (1996). A novel method for continuous determination of the intracellular $\mathrm{pH}$ in bacteria with the internally conjugated fluorescent probe 5 (and 6-)-carboxyfluorescein succinimidyl ester. Appl. Environ. Microbiol. 62, 178-183.

Brenes, A., and Roura, E. (2010). Essential oils in poultry nutrition: main effects and modes of action. Anim. Feed Sci. Technol. 158, 1-14.

Burt, S. (2004). Essential oils: their antibacterial properties and potential applications in foods - a review. Int. J. Food Microbiol. 94, 223-253.

Burt, S. A., and Reinders, R. D. (2003). Antibacterial activity of selected plant essential oils against Escherichia coli O157:H7. Lett. Appl. Microbiol. 36, 162-167.

Burt, S. A., Van Der Zee, R., Koets, A. P., De Graaff, A. M., Van Knapen, 
F., Gaastra, W., Haagsman, H. P., and Veldhuizen, E. J. A. (2007). Carvacrol induces heat shock protein 60 and inhibits synthesis of flagellin in Escherichia coli O157:H7. Appl. Environ. Microbiol. 73, 4484-4490.

Caballero, B., Trugo, L. C., and Finglas, P. M. (2003). Encyclopedia of Food Sciences and Nutrition. Amsterdam: Academic Press.

Carson, C. F., Mee, B. J., and Riley, T. V. (2002). Mechanism of action of Melaleuca alternifolia (tea tree) oil on Staphylococcus aureus determined by time-kill, lysis, leakage, and salt tolerance assays and electron microscopy. Antimicrob. Agents Chemother. 46, 1914-1920.

Carson, C. F., and Riley, T. V. (1995). Antimicrobial activity of the major components of the essential oil of Melaleuca alternifolia. J. Appl. Bacteriol. 78, 264-269.

Cavallito, C. J., and Bailey, J. H. (1944), Allicin, the antibacterial principle of Allium sativum. I. Isolation, physical properties and antibacterial action. J. Am. Chem. Soc. 66, 1950-1951.

Cava-Roda, R., Taboada-Rodríguez, A., Valverde-Franco, M., and MarínIniesta, F. (2010). Antimicrobial activity of vanillin and mixtures with cinnamon and clove essential oils in controlling Listeria monocytogenes and Escherichia coli O157:H7 in milk. Food Bioprocess Technol. doi: 10.1007/s11947-010-0484-4

Cejpek, K., Valusek, J., and Velisek, J. (2000). Reactions of allyl isothiocyanate with alanine, glycine, and several peptides in model systems. J. Agric. Food Chem. 48, 3560-3565.

Cerrutti, P., and Alzamora, S. M. (1996). Inhibitory effects of vanillin on some food spoilage yeasts in laboratory media and fruit purées. Int. J. Food Microbiol. 29, 379-386.

Ceylan, E., and Fung, D. Y. C. (2004). Antimicrobial activity of spices. $J$. Rapid Methods Autom. Microbiol. 12, $1-55$.

Chang, S. T., Chen, P. F., and Chang, S. C. (2001). Antibacterial activity of leaf essential oils and their constituents from Cinnamomum osmophloeum. J. Ethnopharmacol. 77, 123-127.

Cimanga, K., Kambu, K., Tona, L., Apers, S., De Bruyne, T., Hermans, N., Totté, J., Pieters, L., and Vlietinck, A. J. (2002). Correlation between chemical composition and antibacterial activity of essential oils of some aromatic medicinal plants growing in the Democratic Republic of Congo. J. Ethnopharmacol. 79, 213-220.

Claeson, P., Radstrom, P., Skold, O., Nilsson, A., and Hoglund, S. (1992).
Bactericidal effect of the sesquiterpene T-cadinol on Staphylococcus aureus. Phytother. Res. 6, 94-98.

Cosentino, S., Tuberoso, C. I. G., Pisano, B., Satta, M., Mascia, V., Arzedi, E., and Palmas, F. (1999). In-vitro antimicrobial activity and chemical composition of Sardinian Thymus essential oils. Lett. Appl. Microbiol. 29, 130-135.

Cotter, P. D., Hill, C., and Ross, R. P. (2005). Food microbiology: bacteriocins: developing innate immunity for food. Nat. Rev. Microbiol. 3, 777-788.

Cox, S. D., Mann, C. M., Markham, J. L., Bell, H. C., Gustafson, J. E., Warmington, J. R., and Wyllie, S. G. (2000). The mode of antimicrobial action of the essential oil of Melaleuca alternifolia (tea tree oil). J. Appl. Microbiol. 88, 170-175.

Cristani, M., D’Arrigo, M., Mandalari, G., Castelli, F., Sarpietro, M. G., Micieli, D., Venuti, V., Bisignano, G., Saija, A., and Trombetta, D. (2007). Interaction of four monoterpenes contained in essential oils with model membranes: implications for their antibacterial activity. J. Agric. Food Chem. 55, 6300-6308.

Davidson, P. M., and Parish, M. E. (1989). methods for testing the efficacy of food antimicrobials. Food Technol. 43, 148-155.

De, M., De, A. K., and Banerjee, A. B. (1999). Antimicrobial screening of some Indian spices. Phytother. Res. 13, 616-618.

De Oliveira, T. L. C., De Araújo Soares, R., Ramos, E. M., Das Graças Cardoso, M., Alves, E., and Piccoli, R. H. (2011). Antimicrobial activity of Satureja montana L. essential oil against Clostridium perfringens type A inoculated in mortadella-type sausages formulated with different levels of sodium nitrite. Int. J. Food Microbiol. 144, 546-555.

De Souza, E. L., De Barros, J. C., De Oliveira, C. E. V., and Da Conceição, M. L. (2010). Influence of Origanum vulgare L. essential oil on enterotoxin production, membrane permeability and surface characteristics of Staphylococcus aureus. Int. J. Food Microbiol. 137, 308-311.

De Souza, E. L., Stamford, T. L. M., Lima, E. D. O., Barbosa Filho, J. M., and Marques, M. O. M. (2008). Interference of heating on the antimicrobial activity and chemical composition of Origanum vulgare L. (Lamiaceae) essential oil. Ciênc. Tecnol. Aliment. 28, 418-422.

Deans, S. G., and Ritchie, G. (1987). Antibacterial properties of plant essential oils. Int. J. Food Microbiol. 5, 165-180.

Delaquis, P. (1995). Antimicrobial properties of isothiocyanates in food preservation. Food Technol. 49, 73.

Delaquis, P. (1997). Antimicrobial activity of gaseous allyl isothiocyanate. J. Food Prot. 60, 943.

Delaquis, P. J., Stanich, K., Girard, B. and Mazza, G. (2002). Antimicrobial activity of individual and mixed fractions of dill, cilantro, coriander and eucalyptus essential oils. Int. J. Food Microbiol. 74, 101-109.

Demuner, A. J., Barbosa, L. C. A., Magalhaes, C. G., Da Silva, C. J., Maltha, C. R. A., and Pinheiro, A. L. (2011). Seasonal variation in the chemical composition and antimicrobial activity of volatile oils of three species of Leptospermum (Myrtaceae) grown in Brazil. Molecules 16, 1181-1191.

Di Pasqua, R., Betts, G., Hoskins, N. Edwards, M., Ercolini, D., and Mauriello, G. (2007). Membrane toxicity of antimicrobial compounds from essential oils. J. Agric. Food Chem. 55, 4863-4870.

Di Pasqua, R., Hoskins, N., Betts, G., and Mauriello, G. (2006). Changes in membrane fatty acids composition of microbial cells induced by addiction of thymol, carvacrol, limonene, cinnamaldehyde, and eugenol in the growing media. J. Agric. Food Chem. 54, 2745-2749.

Di Pasqua, R., Mamone, G., Ferranti, P., Ercolini, D., and Mauriello, G. (2010). Changes in the proteome of Salmonella enterica serovar Thompson as stress adaptation to sublethal concentrations of thymol. Proteomics 10, 1040-1049.

Djenane, D., Yangüela, J., Montañés, L., Djerbal, M., and Roncalés, P. (2011). Antimicrobial activity of Pistacia lentiscus and Satureja montana essential oils against Listeria monocytogenes CECT 935 using laboratory media: efficacy and synergistic potential in minced beef. Food Control 22, 1046-1053.

Domadia, P., Swarup, S., Bhunia, A., Sivaraman, J., and Dasgupta, D. (2007). Inhibition of bacterial cell division protein FtsZ by cinnamaldehyde. Biochem. Pharmacol. 74, 831-840.

Donsí, F., Annunziata, M., Sessa, M., and Ferrari, G. (2011). Nanoencapsulation of essential oils to enhance their antimicrobial activity in foods. Food Sci. Technol. 44, 1908-1914.

Dorman, H. J. D., and Deans, S. G. (2000). Antimicrobial agents from plants: antibacterial activity of plant volatile oils. J. Appl. Microbiol. 88, 308-316.
Dufrêne, Y. F. (2008). Towards nanomicrobiology using atomic force microscopy. Nat. Rev. Microbiol. 6, 674-680.

Eliopoulos, G. M., Moellering, R. C. J., and Pillai, S. K. (1996). "Antimicrobial combinations," in Antibiotics in Laboratory Medicine, 5th Edn, ed. V. Lorian (Philadelphia: Williams \& Wilkins), 365-440.

Espina, L., Somolinos, M., Lorán, S., Conchello, P., García, D., and Pagán, R. (2011). Chemical composition of commercial citrus fruit essential oils and evaluation of their antimicrobial activity acting alone or in combined processes. Food Control 22, 896-902.

Essam, E. (2001). Insecticidal activity of essential oils: octopaminergic sites of action. Comp. Biochem. Physiol. C Toxicol. Pharmacol. 130, 325-337.

Fantner, G. E., Barbero, R. J., Gray, D. S., and Belcher, A. M. (2010). Kinetics of antimicrobial peptide activity measured on individual bacterial cells using high-speed atomic force microscopy. Nat. Nanotechnol. 5, 280-285.

Feldberg, R. S., Chang, S. C., Kotik, A. N., Nadler, M., Neuwirth, Z., Sundstrom, D. C., and Thompson, N. H. (1988). In vitro mechanism of inhibition of bacterial cell growth by allicin. Antimicrob. Agents Chemother. 32, 1763-1768.

Feron, V. J., Til, H. P., De Vrijer, F., Woutersen, R. A., Cassee, F. R., and Van Bladeren, P. J. (1991). Aldehydes: occurrence, carcinogenic potential, mechanism of action and risk assessment. Mutat. Res. 259, 363-385.

Fisher, K., and Phillips, C. (2008). Potential antimicrobial uses of essential oils in food: is citrus the answer? Trends Food Sci. Technol. 19, 156-164.

Fisher, K., and Phillips, C. (2009). The mechanism of action of a citrus oil blend against Enterococcus faecium and Enterococcus faecalis. J. Appl. Microbiol. 106, 1343-1349.

Fisher, K., and Phillips, C. A. (2006). The effect of lemon, orange and bergamot essential oils and their components on the survival of Campylobacter jejuni, Escherichia coli O157, Listeria monocytogenes, Bacillus cereus and Staphylococcus aureus in vitro and in food systems. J. Appl. Microbiol. 101, 1232-1240.

Fitzgerald, D. J., Stratford, M., Gasson, M. J., and Narbad, A. (2005). Structure-function analysis of the vanillin molecule and its antifungal properties. J. Agric. Food Chem. 53, 1769-1775.

Fitzgerald, D. J., Stratford, M., Gasson, M. J., Ueckert, J., Bos, A., and 
Narbad, A. (2004). Mode of antimicrobial of vanillin against Escherichia coli, Lactobacillus plantarum and Listeria innocua. J. Appl. Microbiol. 97, 104-113.

Fitzgerald, D. J., Stratford, M., and Narbad, A. (2003). Analysis of the inhibition of food spoilage yeasts by vanillin. Int. J. Food Microbiol. 86, 113-122.

Focke, M., Feld, A., and Lichtenthaler, H. K. (1990). Allicin, a naturally occurring antibiotic from garlic, specifically inhibits acetyl-CoA synthetase. FEBS Lett. 261, 106-108.

Fraenkel, G. S. (1959). The raison d'être of secondary plant substances. Science 129, 1466-1470.

Gabel, C. V., and Berg, H. C. (2003). The speed of the flagellar rotary motor of Escherichia coli varies linearly with protonmotive force. Proc. Natl. Acad. Sci. U.S.A. 100, 8748-8751.

Gao, C., Tian, C., Lu, Y., Xu, J., Luo, J., and Guo, X. (2011). Essential oil composition and antimicrobial activity of Sphallerocarpus gracilis seeds against selected foodrelated bacteria. Food Control 22, 517-522.

García-García, R., López-Malo, A., and Palou, E. (2011). Bactericidal action of binary and ternary mixtures of carvacrol, thymol, and eugenol against Listeria innocua. J. Food Sci. 76, M95-M100.

George, D. R., Smith, T. J., Shiel, R. S., Sparagano, O. A. E., and Guy, J. H. (2009). Mode of action and variability in efficacy of plant essential oils showing toxicity against the poultry red mite, Dermanyssus gallinae. Vet. Parasitol. 161, 276-282.

Ghannoum, M. A., and Rice, L. B. (1999). Antifungal agents: mode of action, mechanisms of resistance, and correlation of these mechanisms with bacterial resistance. Clin. Microbiol. Rev. 12, 501-517.

Gilbert, Y., Deghorain, M., Wang, L., $\mathrm{Xu}$, B., Pollheimer, P. D., Gruber, H. J., Errington, J., Hallet, B., Haulot, X., Verbelen, C., Hols, P., and Dufrêne, Y. F. (2007). Singlemolecule force spectroscopy and imaging of the vancomycin/D-AlaD-Ala interaction. Nano Lett. 7, 796-801.

Gill, A. O., Delaquis, P., Russo, P., and Holley, R. A. (2002). Evaluation of antilisterial action of cilantro oil on vacuum packed ham. Int. J. Food Microbiol. 73, 83-92.

Gill, A. O., and Holley, R. A. (2004). Mechanisms of bactericidal action of cinnamaldehyde against Listeria monocytogenes and of eugenol against L. monocytogenes and Lactobacillus sakei. Appl. Environ. Microbiol. 70, 5750-5755.

Gill, A. O., and Holley, R. A. (2006a). Disruption of Escherichia coli, Listeria monocytogenes and Lactobacillus sakei cellular membranes by plant oil aromatics. Int. J. Food Microbiol. 108, 1-9.

Gill, A. O., and Holley, R. A. (2006b). Inhibition of membrane bound ATPases of Escherichia coli and Listeria monocytogenes by plant oil aromatics. Int. J. Food Microbiol. 111, 170-174.

Gustafson, J. E., Liew, Y. C., Chew, S., Markham, J., Bell, H. C., Wyllie, S. G., and Warmington, J. R. (1998). Effects of tea tree oil on Escherichia coli. Lett. Appl. Microbiol. 26, 194-198.

Gutierrez, J., Barry-Ryan, C., and Bourke, P. (2008). The antimicrobial efficacy of plant essential oil combinations and interactions with food ingredients. Int. J. Food Microbiol. 124, 91-97.

Gutierrez, J., Barry-Ryan, C., and Bourke, P. (2009). Antimicrobial activity of plant essential oils using food model media: efficacy, synergistic potential and interactions with food components. Food Microbiol. $26,142-150$.

Hafedh, H., Fethi, B. A., Mejdi, S., Emira, N., and Amina, B. (2010). Effect of Mentha longifolia L. ssp longifolia essential oil on the morphology of four pathogenic bacteria visualized by atomic force microscopy. Afr. J. Microbiol. Res. 4, 1122-1127.

Hammer, K. A., Carson, C. F., and Riley, T. V. (1999). Antimicrobial activity of essential oils and other plant extracts. J. Appl. Microbiol. 86, 985-990.

Hartl, F. U., Bracher, A., and HayerHartl, M. (2011). Molecular chaperones in protein folding and proteostasis. Nature 475, 324-332.

Helander, I. M., Alakomi, H. L., LatvaKala, K., Mattila-Sandholm, T., Pol, I., Smid, E. J., Gorris, L. G. M., and Von Wright, A. (1998). Characterization of the action of selected essential oil components on Gramnegative bacteria. J. Agric. Food Chem. 46, 3590-3595.

Hemaiswarya, S., and Doble, M. (2009). Synergistic interaction of eugenol with antibiotics against Gram negative bacteria. Phytomedicine 16, 997-1005.

Hemaiswarya, S., Soudaminikkutty, R., Narasumani, M. L., and Doble, M. (2011). Phenylpropanoids inhibit protofilament formation of Escherichia coli cell division protein FtsZ. J. Med. Microbiol. 60, 1317-1325.

Horváth, G., Kovács, K., Kocsis, B., and Kustos, I. (2009). Effect of thyme (Thymus vulgaris L.) essential oil and its main constituents on the outer membrane protein composition of erwinia strains studied with microfluid chip technology. Chromatographia 70, 1645-1650.

Hughes, B. G., and Lawson, L. D. (1991). Antimicrobial effects of Allium sativum L. (garlic), Allium ampeloprasum L. (elephant garlic), and Allium cepa L. (onion), garlic compounds and commercial garlic supplement products. Phytother. Res. 5, 154-158.

Işcan, G., Kirimer, N., Kürkcüoglu, M. Baser, K. H. C., and Demirci, F. (2002). Antimicrobial screening of Mentha piperita essential oils. J. Agric. Food Chem. 50, 3943-3946.

Jung, H. G., and Fahey, G. C. (1983). Nutritional implications of phenolic monomers and lignin: a review. J. Anim. Sci. 57, 206-219.

Juven, B. J., Kanner, J., Schved, F., and Weisslowicz, H. (1994). Factors that interact with the antibacterial action of thyme essential oil and its active constituents. J. Appl. Bacteriol. 76, 626-631.

Kalemba, D., and Kunicka, A. (2003). Antibacterial and antifungal properties of essential oils. Curr. Med. Chem. 10, 813-829.

Kawakishi, S., and Kaneko, T. (1985) Interaction of oxidized glutathione with allyl isothiocyanate. Phytochemistry 24, 715-718.

Kawakishi, S., and Kaneko, T. (1987). Interaction of proteins with allyl isothiocyanate. J. Agric. Food Chem. 35, 85-88.

Kawakishi, S., and Namiki, M. (1982). Oxidative cleavage of the disulfide bond of cystine by allyl isothiocyanate. J. Agric. Food Chem. 30, 618-620.

Kim, J., Marshall, M. R., and Wei, C. I. (1995). Antibacterial activity of some essential oil components against five foodborne pathogens. $J$. Agric. Food Chem. 43, 2839-2845.

Kim, S. I., Roh, J. Y., Kim, D. H., Lee, H S., and Ahn, Y. J. (2003). Insecticidal activities of aromatic plant extracts and essential oils against Sitophilus oryzae and Callosobruchus chinensis. J Stored Prod Res 39, 293-303.

Kojima, M. (1971). Studies on the effects of isothiocyanates and their analogues on microorganisms. J. Ferment. Technol. 49, 740-746.

Koutsoudaki, C., Krsek, M., and Rodger, A. (2005). Chemical composition and antibacterial activity of the essential oil and the gum of Pistacia lentiscus Var. chia. J. Agric. Food Chem. 53, 7681-7685.

Kumar, M., and Berwal, J. S. (1998). Sensitivity of food pathogens to garlic (Allium sativum). J. Appl. Microbiol. 84, 213-215.

Kwon, J. A., Yu, C. B., and Park, H. D. (2003). Bacteriocidal effects and inhibition of cell separation of cinnamic aldehyde on Bacillus cereus. Lett. Appl. Microbiol. 37, 61-65.

Kyung, K. H. (2011). Antimicrobial properties of Allium species. Curr. Opin. Biotechnol. doi: 10.1016/j.copbio.2011.08.004

La Storia, A., Ercolini, D., Marinello, F., Di Pasqua, R., Villani, F., and Mauriello, G. (2011). Atomic force microscopy analysis shows surface structure changes in carvacroltreated bacterial cells. Res. Microbiol. 162, 164-172.

Laekeman, G. M., Van Hoof, L. Haemers, A., Berghe, D. A. V., Herman, A. G., and Vlietinck, A. J. (1990). Eugenol a valuable compound for in vitro experimental research and worthwhile for further in vivo investigation. Phytother. Res. 4, 90-96.

Lambert, P. A., and Hammond, S. M. (1973). Potassium fluxes, first indications of membrane damage in micro-organisms. Biochem. Biophys. Res. Commun. 54, 796-799.

Lambert, R. J. W., Skandamis, P. N., Coote, P. J., and Nychas, G. J. E. (2001). A study of the minimum inhibitory concentration and mode of action of oregano essential oil, thymol and carvacrol. J. Appl. Microbiol. 91, 453-462.

Liao, H., Zhang, F., Liao, X., Hu, X., Chen, Y., and Deng, L. (2010). Analysis of Escherichia coli cell damage induced by HPCD using microscopies and fluorescent staining. Int. J. Food Microbiol. 144, 169-176.

Lin, C. M., Preston Iii, J. F., and Wei, C. I. (2000). Antibacterial mechanism of allyl isothiocyanate. J. Food Prot. 63, 727-734.

Liu, S., Sun, Y., Li, W., Yu, H., Li, X., Liu, Z., Zeng, J., Zhou, Y., Chen, C., and Jia, J. (2010). The antibacterial mode of action of allitridi for its potential use as a therapeutic agent against Helicobacter pylori infection. FEMS Microbiol. Lett. 303, 183-189.

Luciano, F. B., and Holley, R. A. (2009). Enzymatic inhibition by allyl isothiocyanate and factors affecting its antimicrobial action against Escherichia coli O157:H7. Int. J. Food Microbiol. 131, 240-245.

Luciano, F. B., Hosseinian, F. S., Beta, T., and Holley, R. A. (2008). Effect 
of free-SH containing compounds on allyl isothiocyanate antimicrobial activity against Escherichia coli O157:H7. J. Food Sci. 73, M214M220.

Lv, F., Liang, H., Yuan, Q., and Li, C. (2011). In vitro antimicrobial effects and mechanism of action of selected plant essential oil combinations against four food-related microorganisms. Food Res. Int. 44, 3057-3064.

Mann, C. M., Cox, S. D., and Markham, J. L. (2000). The outer membrane of Pseudomonas aeruginosa NCTC 6749 contributes to its tolerance to the essential oil of Melaleuca alternifolia (tea tree oil). Lett. Appl. Microbiol. 30, 294-297.

Marino, M., Bersani, C., and Comi, G. (2001). Impedance measurements to study the antimicrobial activity of essential oils from Lamiaceae and Compositae. Int. J. Food Microbiol. 67, 187-195.

Miron, T., Rabinkov, A., Mirelman, D., Wilchek, M., and Weiner, L. (2000). The mode of action of allicin: its ready permeability through phospholipid membranes may contribute to its biological activity. Biochim. Biophys. Acta 1463, 20-30.

Nakamura, C. V., Ueda-Nakamura, T., Bando, E., Negrão Melo, A. F., Garcia Cortez, D. A., and Dias Filho Filho, B. P. (1999). Antibacterial activity of Ocimum gratissimum L. essential oil. Mem. Inst. Oswaldo Cruz 94, 675-678.

Nannapaneni, R., Chalova, V. I., Crandall, P. G., Ricke, S. C., Johnson, M. G., and O'Bryan, C. A. (2009). Campylobacter and Arcobacter species sensitivity to commercial orange oil fractions. Int. J. Food Microbiol. 129, 43-49.

Nazer, A. I., Kobilinsky, A., Tholozan, J. L., and Dubois-Brissonnet, F. (2005). Combinations of food antimicrobials at low levels to inhibit the growth of Salmonella sv. Typhimurium: a synergistic effect? Food Microbiol. 22, 391-398.

Nguefack, J., Budde, B. B., and Jakobsen, M. (2004a). Five essential oils from aromatic plants of Cameroon: their antibacterial activity and ability to permeabilize the cytoplasmic membrane of Listeria innocua examined by flow cytometry. Lett. Appl. Microbiol. 39, 395-400.

Nguefack, J., Leth, V., Amvam Zollo, P. H., and Mathur, S. B. (2004b). Evaluation of five essential oils from aromatic plants of Cameroon for controlling food spoilage and mycotoxin producing fungi. Int. J. Food Microbiol. 94, 329-334.
Nguefack, J., Tamgue, O., Dongmo, J. B. L., Dakole, C. D., Leth, V., Vismer, H. F., Amvam Zollo, P. H., and Nkengfack, A. E. (2012). Synergistic action between fractions of essential oils from Cymbopogon citratus, Ocimum gratissimum and Thymus vulgaris against Penicillium expansum. Food Control 23, 377-383.

Nielsen, P. V., and Rios, R. (2000). Inhibition of fungal growth on bread by volatile components from spices and herbs, and the possible application in active packaging, with special emphasis on mustard essential oil. Int. J. Food Microbiol. 60, 219-229.

Nielsen, S. B., and Otzen, D. E. (2010). Impact of the antimicrobial peptide novicidin on membrane structure and integrity. J. Colloid Interface Sci. 345, 248-256.

Nikaido, H. (1994). Prevention of drug access to bacterial targets: permeability barriers and active efflux. Science 264, 382-388.

Nikaido, H. (2003). Molecular basis of bacterial outer membrane permeability revisited. Microbiol. Mol. Biol. Rev. 67, 593-656.

Odds, F. C. (2003). Synergy, antagonism, and what the chequerboard puts between them. J. Antimicrob. Chemother. 52, 1.

Onawunmi, G. O. (1989). Evaluation of the antimicrobial activity of citral. Lett. Appl. Microbiol. 9, 105-108.

Oussalah, M., Caillet, S., and Lacroix, M. (2006). Mechanism of action of Spanish oregano, Chinese cinnamon, and savory essential oils against cell membranes and walls of Escherichia coli O157:H7 and Listeria monocytogenes. J. Food Prot. 69, 1046-1055

Oussalah, M., Caillet, S., Saucier, L., and Lacroix, M. (2007). Inhibitory effects of selected plant essential oils on the growth of four pathogenic bacteria: E. coli O157:H7, Salmonella typhimurium, Staphylococcus aureus and Listeria monocytogenes. Food Control 18, 414-420.

Paibon, W., Yimnoi, C. A., Tembab, N., Boonlue, W., Jampachaisri, K., Nuengchamnong, N., Waranuch, N., and Ingkaninan, K. (2011). Comparison and evaluation of volatile oils from three different extraction methods for some Thai fragrant flowers. Int. J. Cosmet. Sci. 33, 150-156.

Pajohi, M. R. (2011). Synergistic antibacterial activity of the essential oil of Cuminum cyminum seed and nisin in a food model. J. Appl. Microbiol. 110, 943.

Panizzi, L., Flamini, G., Cioni, P. L., and Morelli, I. (1993). Composition and antimicrobial properties of essential oils of four mediterranean lamiaceae. J. Ethnopharmacol. 39, 167-170.

Paparella, A., Taccogna, L., Aguzzi, I., Chaves-López, C., Serio, A., Marsilio, F., and Suzzi, G. (2008). Flow cytometric assessment of the antimicrobial activity of essential oils against Listeria monocytogenes. Food Contro 19, 1174-1182.

Paul, S. (2011). Trachyspermum amm (L.) fruit essential oil influencing on membrane permeability and surface characteristics in inhibiting food borne pathogens. Food Control 22, 725.

Pauli, A., and Kubeczka, K. H. (2010). Antimicrobial properties of volatile phenylpropanes. Nat. Prod. Commun. 5, 1387-1394.

Pei, R. S., Zhou, F., Ji, B. P., and Xu, J. (2009). Evaluation of combined antibacterial effects of eugenol, cinnamaldehyde, thymol, and carvacrol against $E$. coli with an improved method. J. Food Sci. 74, M379-M383.

Pelissari, F. M., Grossmann, M. V. E., Yamashita, F., and Pined, E. A. G. (2009). Antimicrobial, mechanical, and barrier properties of cassava starch-chitosan films incorporated with oregano essential oil. J. Agric. Food Chem. 57, 7499-7504.

Pereira, C. G., and Meireles, M. A. A. (2010). Supercritical fluid extraction of bioactive compounds: fundamentals, applications and economic perspectives. Food Bioprocess Technol. 3, 340-372.

Pérez-Fons, L., Aranda, F. J., Guillén, J., Villalaín, J., and Micol, V. (2006). Rosemary (Rosmarinus officinalis) diterpenes affect lipid polymorphism and fluidity in phospholipid membranes. Arch. Biochem. Biophys. 453, 224-236.

Perry, C. C., Weatherly, M., Beale, T., and Randriamahefa, A. (2009). Atomic forcemicroscopy study of the antimicrobial activity of aqueous garlic versus ampicillin against Escherichia coli and Staphylococcus aureus. J. Sci. Food Agric. 89, 958-964.

Phillips, C., and Laird, K. (2011). Vapour of a citrus essential oil blend and its antimicrobial properties. U.S. Patent 20110136761.

Rabinkov, A., Miron, T., Konstantinovski, L., Wilchek, M., Mirelman, D., and Weiner, L. (1998). The mode of action of allicin: trapping of radicals and interaction with thiol containing proteins. Biochim. Biophys. Acta 1379, 233-244.
Rammanee, K., and Hongpattarakere, T. (2011). Effects of tropical citrus essential oils on growth, aflatoxin production, and ultrastructure alterations of Aspergillus flavus and Aspergillus parasiticus. Food Bioprocess Technol. 4, 1050-1059.

Rao, A., Zhang, Y., Muend, S., and Rao, R. (2010). Mechanism of antifungal activity of terpenoid phenols resembles calcium stress and inhibition of the TOR pathway. Antimicrob. Agents Chemother. 54, 5062-5069.

Rasooli, I., Rezaei, M. B., and Allameh, A. (2006). Ultrastructural studies on antimicrobial efficacy of thyme essential oils on Listeria monocytogenes. Int. J. Infect. Dis. 10, 236-241.

Rattanachaikunsopon, P., and Phumkhachorn, P. (2010). Assessment of factors influencing antimicrobial activity of carvacrol and cymene against Vibrio cholerae in food. J. Biosci. Bioeng. 110, 614-619.

Rhayour, K., Bouchikhi, T., TantaouiElaraki,A., Sendide, K., and Remmal, A. (2003). The mechanism of bactericidal action of oregano and clove essential oils and of their phenolic major components on Escherichia coli and Bacillus subtilis. J. Essent. Oil Res. 15, 356-362.

Roller, S. (2003). Natural Antimicrobials for the Minimal Processing of Foods. Cambridge: Woodhead Publishing, Limited.

Romero, D., Aguilar, C., Losick, R., and Kolter, R. (2010). Amyloid fibers provide structural integrity to Bacillus subtilis biofilms. Proc. Natl. Acad. Sci. U.S.A. 107, 2230-2234.

Rupasinghe, H. P. V., Boulter-Bitzer, J., Ahn, T., and Odumeru, J. A. (2006). Vanillin inhibits pathogenic and spoilage microorganisms in vitro and aerobic microbial growth in fresh-cut apples. Food Res. Int. 39, 575-580.

Sánchez, E., García, S., and Heredia, N. (2010). Extracts of edible and medicinal plants damage membranes of Vibrio cholerae. Appl. Environ. Microbiol. 76, 6888-6894.

Sánchez-González, L., Vargas, M., González-Martínez, C., Chiralt, A., and Cháfer, M. (2011). Use of essential oils in bioactive edible coatings: a review. Food Eng. Rev. 3, 1-16.

Scallan, E., Hoekstra, R. M., Angulo, F. J., Tauxe, R. V., Widdowson, M. A., Roy, S. L., Jones, J. L., and Griffin, P. M. (2011). Foodborne illness acquired in the United States-major pathogens. Emerging Infect. Dis. 17, 7-15. 
Schipilliti, L., Dugo, G., Santi, L., Dugo, P., and Mondello, L. (2011). Authentication of bergamot essential oil by gas chromatography-combustionisotope ratio mass spectrometer (GC-C-IRMS). J. Essent. Oil Res. 23, 60-71.

Schneider, T., Kruse, T., Wimmer, R., Wiedemann, I., Sass, V., Pag, U., Jansen, A., Nielsen, A. K., Mygind, P. H., Raventós, D. S., Neve, S., Ravn, B., Bonvin, A. M. J. J., De Maria, L., Andersen, A. S., Gammelgaard, L. K., Sahl, H. G., and Kristensen, H. H. (2010). Plectasin, a fungal defensin, targets the bacterial cell wall precursor lipid II. Science 328, 1168-1172.

Schnitzler, P., Astani, A., and Reichling, J. (2011). Screening for antiviral activities of isolated compounds from essential oils. Evid. Based Complement. Alternat. Med. PMID: 253643

Shapira, R., and Mimran, E. (2007). Isolation and characterization of Escherichia coli mutants exhibiting altered response to thymol. Microb. Drug Resist. 13, 157-165.

Shofran, B. G., Purrington, S. T., Breidt, F., and Fleming, H. P. (1998). Antimicrobial properties of sinigrin and its hydrolysis products. J. Food Sci. 63, 621-624.

Sikkema, J., De Bont, J. A. M., and Poolman, B. (1995). Mechanisms of membrane toxicity of hydrocarbons. Microbiol. Rev. 59, 201-222.

Silva, F., Ferreira, S., Duarte, A., Mendonça, D. I., and Domingues, F. C. (2011). Antifungal activity of Coriandrum sativum essential oil, its mode of action against Candida species and potential synergism with amphotericin B. Phytomedicine 19, 42-47.

Smith-Palmer, A., Stewart, J., and Fyfe, L. (1998). Antimicrobial properties of plant essential oils and essences against five important food-borne pathogens. Lett. Appl. Microbiol. 26, 118-122.

Somolinos, M., García, D., Condón, S., Mackey, B., and Pagán, R. (2010). Inactivation of Escherichia coli by citral. J. Appl. Microbiol. 108, 1928-1939.

Sullan, R. M. A., Li, J. K., Hao, C., Walker, G. C., and Zou, S. (2010). Cholesterol-dependent nanomechanical stability of phasesegregated multicomponent lipid bilayers. Biophys. J. 99, 507-516.

Tajkarimi, M. M., Ibrahim, S. A., and Cliver, D. O. (2010). Antimicrobial herb and spice compounds in food. Food Control 21, 1199-1218.

Thoroski, J. (1989). Eugenol induced inhibition of extracellular enzyme production by Bacillus cereus. J. Food Prot. 52, 399-403.

Trombetta, D., Castelli, F., Sarpietro, M. G., Venuti, V., Cristani, M., Daniele, C., Saija, A., Mazzanti, G., and Bisignano, G. (2005). Mechanisms of antibacterial action of three monoterpenes. Antimicrob. Agents Chemother. 49, 2474-2478.

Tserennadmid, R., Takó, M., Galgóczy, L., Papp, T., Pesti, M., Vágvölgyi, C., Almássy, K., and Krisch, J. (2011). Anti yeast activities of some essential oils in growth medium, fruit juices and milk. Int. J. Food Microbiol. 144, 480-486.

Turgis, M., Han, J., Caillet, S., and Lacroix, M. (2009). Antimicrobial activity of mustard essential oil against Escherichia coli O157:H7 and Salmonella typhi. Food Control 20, 1073-1079.

Turina, A. D. V., Nolan, M. V., Zygadlo, J. A., and Perillo, M. A. (2006). Natural terpenes: self-assembly and membrane partitioning. Biophys. Chem. 122, 101-113.

Ultee, A., Bennik, M. H. J., and Moezelaar, R. (2002). The phenolic hydroxyl group of carvacrol is essential for action against the foodborne pathogen Bacillus cereus. Appl. Environ. Microbiol. 68, 1561-1568.

Ultee, A., Kets, E. P. W., Alberda, M., Hoekstra, F. A., and Smid, E. J. (2000). Adaptation of the food-borne pathogen Bacillus cereus to carvacrol. Arch. Microbiol. 174, 233-238.

Ultee, A., Kets, E. P. W., and Smid, E. J. (1999). Mechanisms of action of carvacrol on the food-borne pathogen. Appl. Environ. Microbiol. 65, 4606-4610.

Ultee, A., and Smid, E. J. (2001). Influence of carvacrol on growth and toxin production by Bacillus cereus. Int. J. Food Microbiol. 64, 373-378.
Van Hoang, K., Stern, N. J., Saxton, A. M., Xu, F., Zeng, X., and Lin, J. (2011). Prevalence, development, and molecular mechanisms of bacteriocin resistance in Campylobacter. Appl. Environ. Microbiol. 77, 2309-2316.

Veldhuizen, E. J. A., Tjeerdsma-Van Bokhoven, J. L. M., Zweijtzer, C., Burt, S. A., and Haagsman, H. P. (2006). Structural requirements for the antimicrobial activity of carvacrol. J. Agric. Food Chem. 54, 1874-1879.

Verma, R. P. (2003). Synthesis and reactions of 3-oxobutyl isothiocyanate (OB ITC). European J. Org. Chem. 2003, 415-420.

Walsh, S. E., Maillard, J. Y., Russell, A. D., Catrenich, C. E., Charbonneau, D. L., and Bartolo, R. G. (2003). Activity and mechanisms of action of selected biocidal agents on Grampositive and -negative bacteria. $J$. Appl. Microbiol. 94, 240-247.

Wang, J., Soisson, S. M., Young, K., Shoop, W., Kodali, S., Galgoci, A., Painter, R., Parthasarathy, G., Tang, Y. S., Cummings, R., Ha, S., Dorso, K., Motyl, M., Jayasuriya, H., Ondeyka, J., Herath, K., Zhang, C., Hernandez, L., Allocco, J., Basilio, Á. Tormo, J. R., Genilloud, O., Vicente, F., Pelaez, F., Colwell, L., Lee, S. H., Michael, B., Felcetto, T., Gill, C., Silver, L. L., Hermes, J. D., Bartizal, K., Barrett, J., Schmatz, D., Becker, J. W., Cully, D., and Singh, S. B. (2006). Platensimycin is a selective FabF inhibitor with potent antibiotic properties. Nature 441, 358-361.

Ward, S. M., Delaquis, P. J., Holley, R. A., and Mazza, G. (1998). Inhibition of spoilage and pathogenic bacteria on agar and pre-cooked roast beef by volatile horseradish distillates. Food Res. Int. 31, 19-26.

Wendakoon, C. N., and Morihiko, S. (1995). Inhibition of amino acid decarboxylase activity of Enterobacter aerogenes by active components in spices. J. Food Prot. 58, 280-283.

Xu, J., Zhou, F., Ji, B. P., Pei, R. S. and $\mathrm{Xu}, \mathrm{N}$. (2008). The antibacterial mechanism of carvacrol and thymol against Escherichia coli. Lett. Appl. Microbiol. 47, 174-179.

Yamazaki, K., Yamamoto, T., Kawai, Y. and Inoue, N. (2004). Enhancement of antilisterial activity of essential oil constituents by nisin and diglycerol fatty acid ester. Food Microbiol. 21, 283-289.

Zemek, J., Kosikova, B., Augustin, J., and Joniak, D. (1979). Antibiotic properties of lignin components. Folia Microbiol. (Praha) 24, 483-486.

Zemek, J., Valent, M., Pódová, M., Košíková, B., and Joniak, D. (1987). Antimicrobiai properties of aromatic compounds of plant origin. Folia Microbiol. (Praha) 32, 421-425.

Zeng, W. C., Zhu, R. X., Jia, L. R., Gao, H., Zheng, Y., and Sun, Q. (2011). Chemical composition, antimicrobial and antioxidant activities of essential oil from Gnaphlium affine. Food Chem. Toxicol. 49, 1322-1328.

Zhang, Y., and Talalay, P. (1994). Anticarcinogenic activities of organic isothiocyanates: chemistry and mechanisms. Cancer Res. 54, 1976s-1981s.

Zink, D. L. (1997). The impact of consumer demands and trends on food processing. Emerging Infect. Dis. 3, 467-469.

Conflict of Interest Statement: The authors declare that the research was conducted in the absence of any commercial or financial relationships that could be construed as a potential conflict of interest.

Received: 01 December 2011; accepted: 09 January 2012; published online: 25 January 2012.

Citation: Hyldgaard M, Mygind T and Meyer RL (2012) Essential oils in food preservation: mode of action, synergies, and interactions with food matrix components. Front. Microbio. 3:12. doi: 10.3389/fmicb.2012.00012

This article was submitted to Frontiers in Antimicrobials, Resistance and Chemotherapy, a specialty of Frontiers in Microbiology.

Copyright (c) 2012 Hyldgaard, Mygind and Meyer. This is an open-access article distributed under the terms of the Creative Commons Attribution Non Commercial License, which permits noncommercial use, distribution, and reproduction in other forums, provided the original authors and source are credited. 